\title{
Percutaneous biopsy and drainage of the pancreas
}

\author{
Virginia Planz ${ }^{1}$. Samuel J. Galgano² (1)
}

Received: 28 June 2021 / Revised: 5 August 2021 / Accepted: 7 August 2021 / Published online: 19 August 2021

(c) The Author(s), under exclusive licence to Springer Science+Business Media, LLC, part of Springer Nature 2021

\begin{abstract}
Percutaneous pancreatic interventions performed by abdominal radiologists play important diagnostic and therapeutic roles in the management of a wide range of pancreatic pathology. While often performed with endoscopy, pancreatic mass biopsy obtained via a percutaneous approach may serve as the only feasible option for diagnosis in patients with post-surgical anatomy, severe cardiopulmonary conditions, or prior non-diagnostic endoscopic attempts. Biopsy of pancreatic transplants are commonly performed percutaneously due to inaccessible location of the allograft by endoscopy, usually in the right lower quadrant or pelvis. Percutaneous drainage of collections in acute pancreatitis is primarily indicated for infection with clinical deterioration and may be performed alone or in combination with endoscopic drainage. Post-surgical pancreatic collections related to pancreatic duct fistula or leak also often warrant therapeutic percutaneous drainage. Knowledge of appropriate indications, strategies of approach, technique, and complications associated with these procedures is critical for a successful clinical practice.
\end{abstract}

Keywords Biopsy $\cdot$ Cross-section interventional radiology $\cdot$ Pancreas $\cdot$ Pancreatic cancer $\cdot$ Pancreatitis $\cdot$ Drainage

\section{Introduction to pancreatic biopsies}

Percutaneous image-guided biopsies are performed daily by most radiology practices and play a significant role in the diagnosis and management of various conditions. However, requests for image-guided biopsies of the pancreas are infrequent, as the vast majority of these are performed via an Endoscopic ultrasound (EUS) approach by gastroenterologists. Thus, radiologists may be uncertain about techniques, approaches, and potential complications for percutaneous image-guided biopsy of the pancreas. Although infrequently requested, percutaneous biopsy of the pancreas has long been reported in the literature with the first major case series published in 1982 [1]. These biopsies were not typically performed prior to the widespread availability of Computed tomography (CT) and development of rapid CT scan times and image reconstruction. However, these

Samuel J. Galgano

samuelgalgano@uabmc.edu

1 Department of Radiology, Vanderbilt University Medical Center, Nashville, TN, USA

2 Department of Radiology, University of Alabama at Birmingham, 619 19th St S, JT J779, Birmingham, AL 35249, USA biopsies may be performed under either CT or Ultrasound (US) guidance, and the approach for biopsy of the native pancreas and transplant pancreas may differ. As a result, it is important for radiologists to understand the potential advantages and disadvantages of both image-guided approaches for the requested procedure.

\section{Rationale for percutaneous vs. endoscopic biopsy approach}

In the diagnostic workup of both solid and cystic pancreatic lesions, core biopsy and/or fine-needle aspiration remain essential. In most patients, the pancreas is easily accessible by endoscopy and EUS, which allows for real-time visualization of the needle. These procedures are almost always performed by gastroenterologists trained in this technique and account for the vast majority of pancreatic biopsies. As a result, gastroenterologists often have far more familiarity and experience in this procedure and routinely perform far more pancreatic biopsies than radiologists. The EUS procedure occurs via a natural orifice, which permits biopsy without a skin puncture or incision, and allows for real-time targeting of specific areas of a lesion that may improve diagnostic yield. Importantly, EUS-guided pancreatic biopsy allows 
for access to many portions of the pancreas without traversing multiple organs along the needle path, which may lead to less complications. These biopsies may be performed as fine-needle aspirations with a 22 gauge or 25-gauge needle, but 18-gauge core biopsies are capable of being obtained [2]. Finally, the performance of EUS is often coupled with Endoscopic retrograde cholangiopancreatography (ERCP), which allows for placement of biliary stents to relieve biliary obstruction at the same time as the diagnostic procedure.

Given that pancreatic biopsies are seldom requested to be performed by radiologists, there can be considerable hesitancy to perform the biopsy. This is primarily due to unfamiliarity of feasibility of percutaneous pancreatic biopsy, fear of potential complications, and the anatomic location of the pancreas. Percutaneous biopsies of the pancreas can be performed as either fine-needle aspirations or core biopsies, allowing for similar sample acquisition to EUS. There are several potential limitations of EUS-guided biopsy which may make a percutaneous approach the only possible or feasible option. First, not all hospitals are staffed by gastroenterologists with training in advanced endoscopy and EUS and this procedure may not be able to be offered to patients (particularly in the rural setting). However, almost all hospitals have the capability of performing CT and USguided biopsies in radiology, which may expedite care of these patients and avoid referral to an outside hospital with EUS capabilities. In patients who are at high risk for sedation, percutaneous biopsies can often be performed with less sedation than a typical endoscopic biopsy. The percutaneous approach may be preferred if there is clinical concern for cardiopulmonary compromise during endoscopy. Also, in patients who have undergone prior gastrointestinal surgery, including Roux-en-Y gastric bypass or prior Billroth resections, retrograde access of the afferent limb may be challenging and requires the use of double-balloon enteroscopy [3]. However, the EUS is often limited by length and may not be able to successfully image portions of the pancreas depending on the patient's gastrointestinal anatomy. In these patients, percutaneous biopsy may be the only option for a diagnosis outside of surgery. Patients who have undergone pancreas transplants also may require biopsies to evaluate for rejection, and given their typical location in the lower quadrants these pancreas biopsies necessitate a percutaneous approach. Finally, endoscopy is considered an aerosol-generating procedure, while percutaneous biopsies are generally not. This aspect became particularly important during the COVID-19 pandemic, when some institutions initially closed endoscopy suites to limit spread of the virus and conserve Personal protective equipment (PPE). Although temporary, at many institutions this led to a multidisciplinary approach to determine alternate approaches to obtain a pathological diagnosis in patients and avoid delays in diagnosis and treatment. Percutaneous biopsy under moderate sedation often utilizes less PPE than endoscopy, although there is considerable variation among institutions and may be a preferred approach in a PPE-limited setting.

\section{Native pancreatic biopsy}

The technique percutaneous biopsy of lesions in the native pancreas was first described in a case series from 1982, which reported a diagnostic accuracy rate of $82 \%$ [1]. These biopsies may be performed as either fine-needle aspirations or core biopsies and can be performed under US or CT guidance. As with many abdominal biopsies, US may be the initial modality of choice, allowing for real-time visualization and guidance of the biopsy needle during the procedure

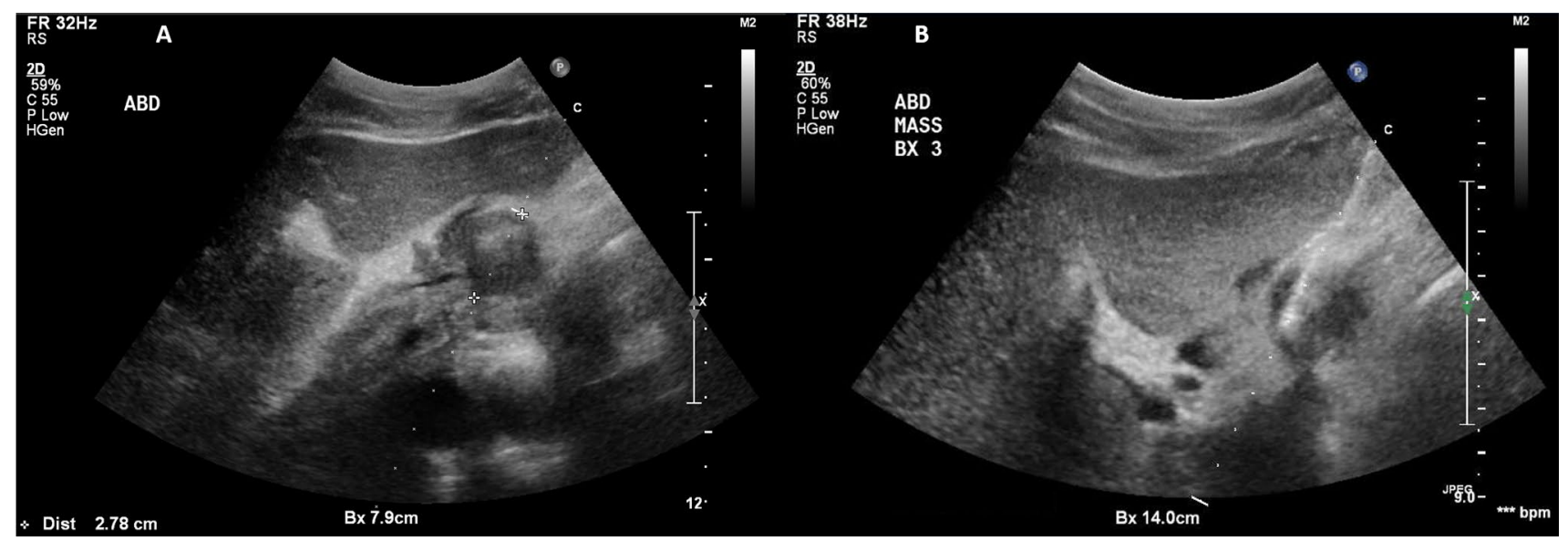

Fig. 1 59-year-old female with suspected pancreatic mass and multiple negative prior endoscopic biopsies. Initial pre-biopsy ultrasound image A demonstrates a hypoechoic pancreatic mass located posterior to the left hepatic lobe. Ultrasound image obtained during the biopsy B demonstrates a transhepatic approach with an 18-gauge core biopsy needle successfully within the pancreatic mass 
(Fig. 1). An initial study of US-guided pancreatic mass fineneedle aspiration in 187 cases found that over $95 \%$ of samples were adequate for cytologic evaluation and a greater than $85 \%$ accuracy rate in differentiating benign and malignant processes [4]. In this study, no false-positive biopsy results were reported, but approximately $13 \%$ of cases resulted in a false-negative result [4]. The false-negative rate of US-guided percutaneous biopsy is within the range of reported false-negative results for endoscopic biopsy, with rates ranging from 5 to $19 \%$ [5-8]. In a separate retrospective review of US-guided pancreatic biopsies, a histologic diagnosis was achieved in $147 / 153$ patients with a sensitivity of $90 \%$ and a specificity of $95 \%$ [9].

The technique for performing US-guided biopsies of the native pancreas begins with an ultrasound of the upper abdomen to determine if the lesion of interest can be visualized. Preprocedural workup for the biopsy should include a review of patient's history and medications and assessment of the platelet count, prothrombin time, and International Normalized Ratio (INR). As per the 2019 Society of Interventional Radiology Guidelines, these biopsies are considered "high-risk" and the recommended thresholds include a platelet count of $50 \times 10^{9} / \mathrm{L}$ or greater and an INR value of less than 1.8 [10]. Patients are instructed to be nil per os for the exam to minimize the effect of bowel gas potentially obscuring the pancreas and to allow for safe administration of moderate sedation during the procedure. Typically, these are performed via an anterior approach with the patient in the supine position and utilize a $4 \mathrm{MHz}$ curved abdominal ultrasound probe. If the lesion of interest can be localized, either a core biopsy or fine-needle aspiration procedure can be performed as per usual institutional guidelines. In some cases, a transhepatic or transgastric approach may be required and a single puncture can be utilized with a trocar technique. Typical postprocedural observation times vary among institutions without consensus, but many centers (including our own) monitor patients for 3-4-h post-biopsy.

The majority of percutaneous native pancreatic biopsies are performed under CT guidance, as the retroperitoneal location of the pancreas and patient body habitus often makes US visualization of the pancreas challenging. Unlike US, CT is not limited by these factors and allows for multiple different approaches for performing a pancreatic biopsy. For example, while CT-guided biopsies may also utilize an anterior (and potential transhepatic or transgastric) approach, they may also be performed from a lateral or posterior approach depending on the location of the pancreatic lesion (Figs. 2, 3, 4). CT-guided biopsies can be performed either utilizing CT fluoroscopy or repeating limited helical CT scans. A recent retrospective review of 82

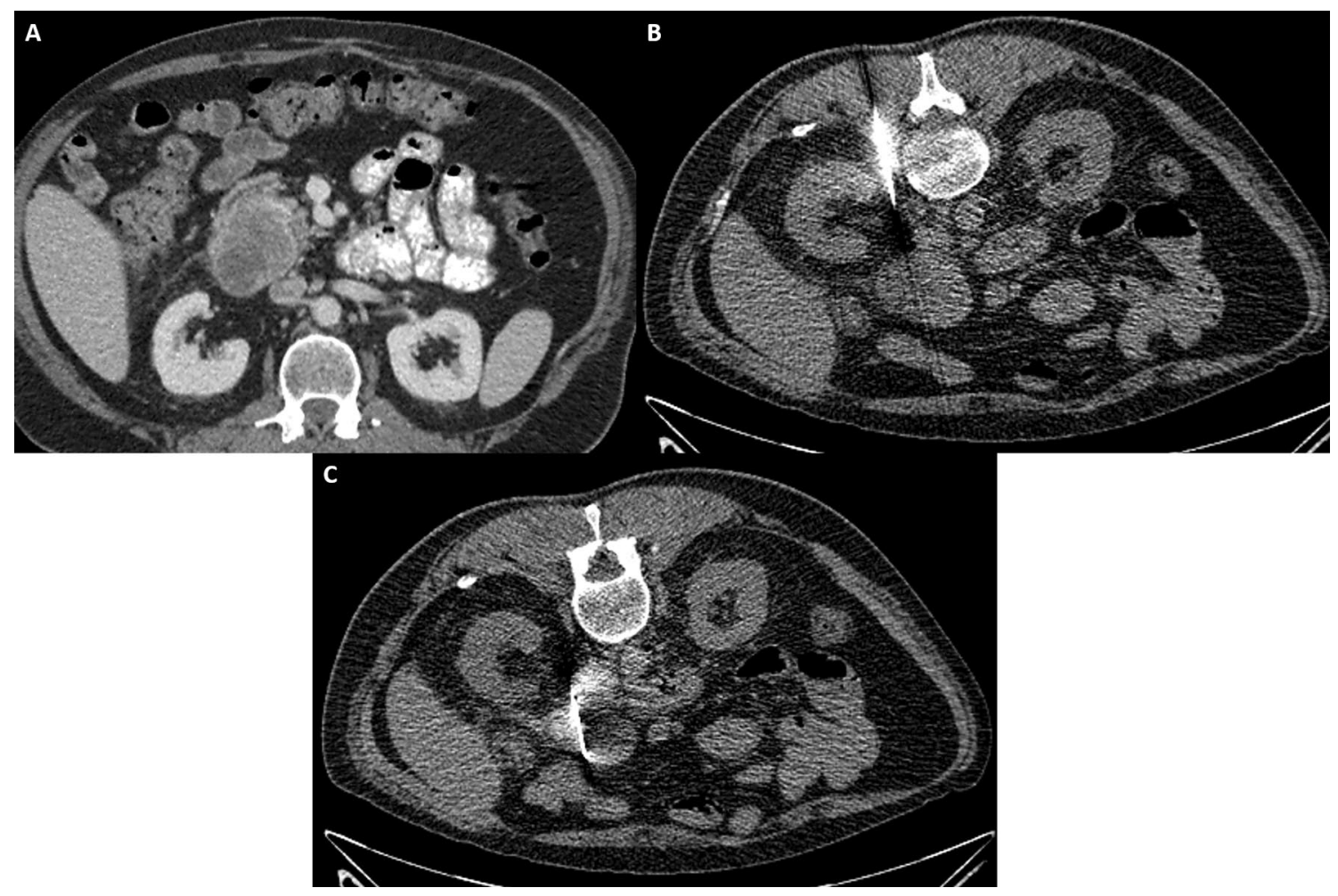

Fig. 2 43-year-old male with suspected enhancing pancreatic head mass diagnosed on CT A during the COVID-19 pandemic with no availability of endoscopy facilities. CT-guided biopsy images $\mathbf{B}$ and
C demonstrate a posterior pararenal approach with successful targeting and biopsy of the pancreatic head lesion 


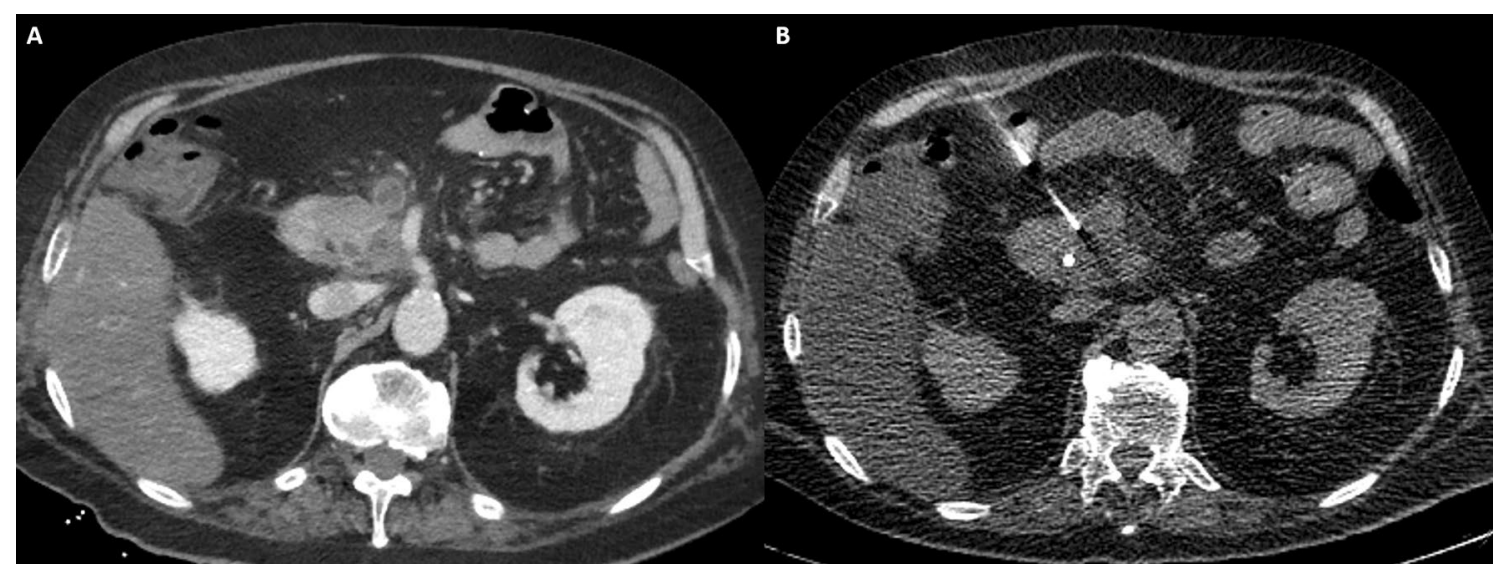

Fig. 3 55-year-old male with history of Roux-en-Y gastric bypass suspected pancreatic head mass and superior mesenteric vein thrombosis status post failed endoscopic biopsy (A). CT-guided biopsy image B demonstrates successful pancreatic biopsy utilizing an anterolateral approach, avoiding adjacent bowel and the thrombosed superior mesenteric vein

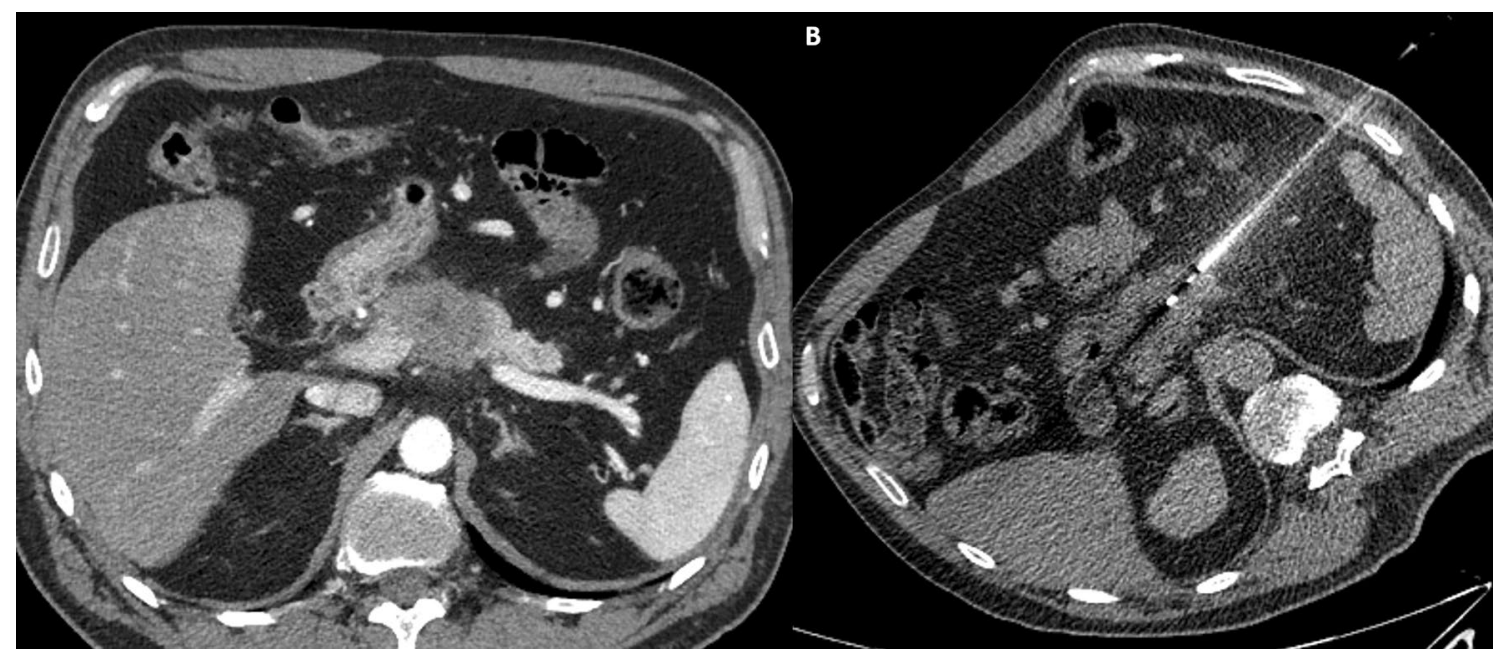

Fig. 4 49-year old male with suspected pancreatic body adenocarcinoma $\mathbf{A}$ status post negative endoscopic biopsies. CT-guided biopsy image B demonstrates a successful lateral approach with the patient

consecutive CT-guided pancreatic biopsies reported that an anterior approach was utilized in $79.3 \%$ of cases, but only necessitated a transgastric/transhepatic approach in $14.6 \%$ [11]. In this study, almost $82 \%$ of biopsies were performed as core biopsies with a needle size ranging from 18 to 22 gauge and a mean number of three samples was obtained [11]. This resulted in a conclusive result in $82.9 \%$ of patients and demonstrated a diagnostic yield similar to EUS fineneedle/core biopsy, prompting the authors to conclude that this approach may be considered where endoscopy facilities are limited [11].

As with any biopsy, there is always a risk of bleeding and infection. Additional unique complications related to native percutaneous pancreatic biopsy (both from an endoscopic and percutaneous approach) include post-biopsy pancreatitis in a slightly oblique position, allowing for displacement of the colon and small bowel along the needle tract

and bowel perforation (Fig. 5). In the published literature, the rates of bleeding are quite low (1-2\%) with only one report of a clinically significant bleeding resulting in patient death $[4,9,11]$. In most cases, bleeding was self-limited and resolved spontaneously. Additionally, no reported infectious complications were noted in the literature, although there are a limited number of manuscripts on the topic. While there is often concern for eliciting an episode of post-biopsy pancreatitis, studies suggest that this is a rare complication with an overall reported rate of post-biopsy pancreatitis ranging from 1.1 to $11 \%$ [11-14]. A study evaluating the risk of a transgastric approach to CT-guided pancreatic biopsy with a 17/18-gauge coaxial needle system found no complications aside from transient pneumoperitoneum that resolved without treatment [15]. It is important for radiologists to 


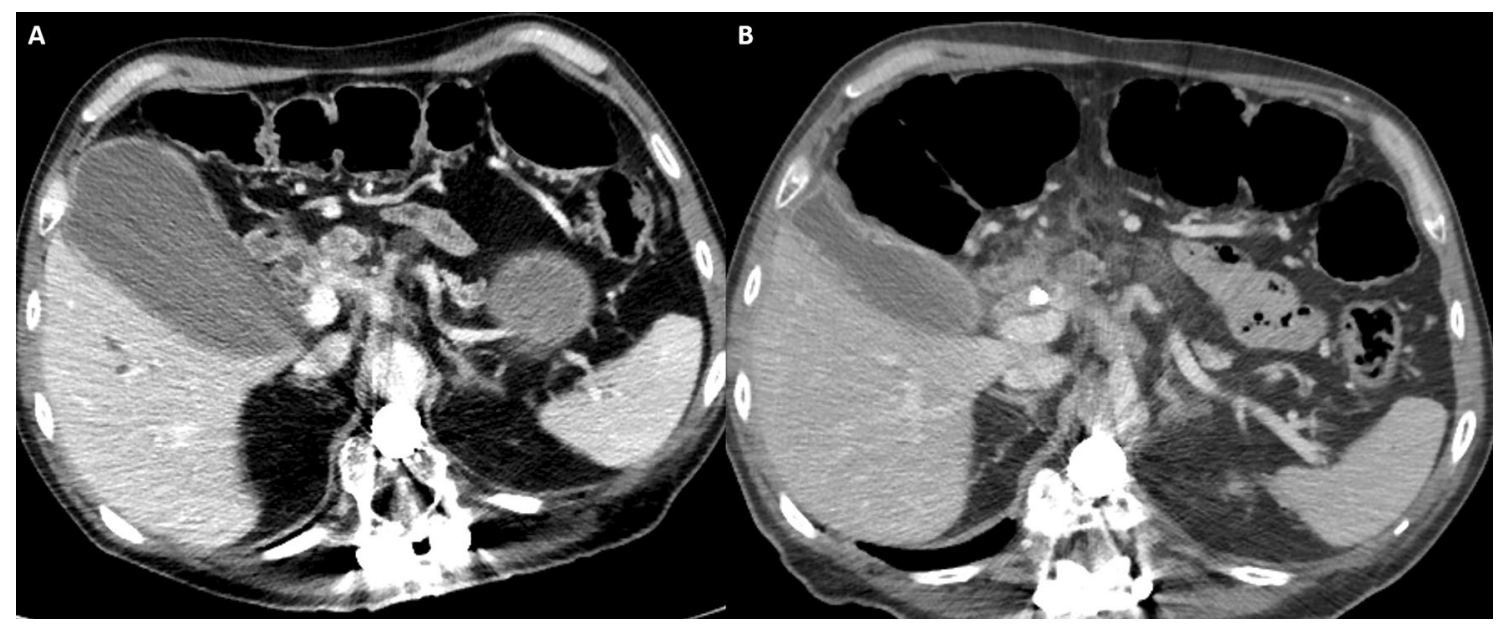

Fig. 5 71-year-old male with pancreatic head mass (not shown) demonstrates an atropic but normal appearance on pre-biopsy CT image (A). Following endoscopic biopsy, CT image demonstrates new peripancreatic stranding, consistent with post-biopsy pancreatitis (B)

understand that when a core biopsy is performed via an endoscopic approach, this procedure always results in a transenteric route and violation of the bowel wall. Published data suggest that even if bowel is transgressed during a biopsy, the rate of frank peritonitis is quite low $(0.3 \%)$ and the benefits of the procedure likely outweigh the risk $[12,16,17]$. Additionally, next-generation sequencing of tumors (including pancreatic tumors) is being performed with increasing frequency and allows for identification of potential targetable mutations. A study evaluating the impact of biopsy (including both percutaneous and endoscopic) on patients with inoperable pancreatic tumors found that biopsy did not adversely affect survival time and demonstrated an estimated relative risk of death in the biopsy cohort of 0.85 when compared to the non-biopsy cohort, illustrating the importance that a tissue sample can have on patient management and outcomes [18].

\section{Transplant pancreatic biopsy}

In contrast to the native pancreas, in many institutions clinicians typically rely on radiologists to perform imageguided biopsies of pancreatic allografts. A major factor in this decision is the anatomic location of the transplant pancreas, which is typically anastomosed to a loop of small bowel in the right lower quadrant or urinary bladder and often performed with a simultaneous kidney transplant. This location is challenging or impossible for endoscopists to reach and thus, a percutaneous approach is often preferred. Similar to other solid organ transplants, histopathology remains the gold standard for evaluating for and staging rejection. For pancreatic transplants, clinical criteria for rejection include monitoring of serum glucose, serum amylase, serum C-peptide level, hemoglobin A1C, and urinary amylase (if bladder drained), but these are non-specific and have a number of alternate etiologies [19]. Causes of pancreatic transplant rejection vary over time, but ultimately an allograft biopsy allows for identification of rejection and the etiology, which will guide management of the patient.

Due to the much more superficial location of the transplant pancreas when compared to the native pancreas, the vast majority of pancreas allograft biopsies are performed under ultrasound guidance. In cases where the transplant pancreas cannot be visualized under ultrasound, CT may be employed to increase confidence of visualization and targeting (Fig. 6). Ultrasound is preferred by many due to the constant peristalsis of adjacent bowel and real-time visualization of both the needle and vascular supply to the allograft (Fig. 7). Typically, once the vascular supply is identified, the needle is directed in a position away from the vasculature to minimize the risk of vascular injury, bleeding, and potential allograft compromise (Fig. 8). An initial study of 35 patients who underwent an ultrasound-guided pancreatic allograft biopsy with standardized histologic grading found a significantly increased graft and patient survival at 1 year [20]. Importantly, in this study acute rejection was only found in $11 \%$ of cases of graft loss and other important histologic findings included identification of endotheliitis, vasculitis, and confluent acinar necrosis; all of which are associated with decreased allograft survival [20]. Using the clinical criteria alone for identification of acute rejection only demonstrated a positive predictive value of $72 \%$, highlighting the importance of biopsy [20]. The diagnostic yield of a percutaneous pancreatic allograft biopsy is high and somewhat dependent on the study and the medical provider performing the biopsy. In two larger studies where biopsies were 


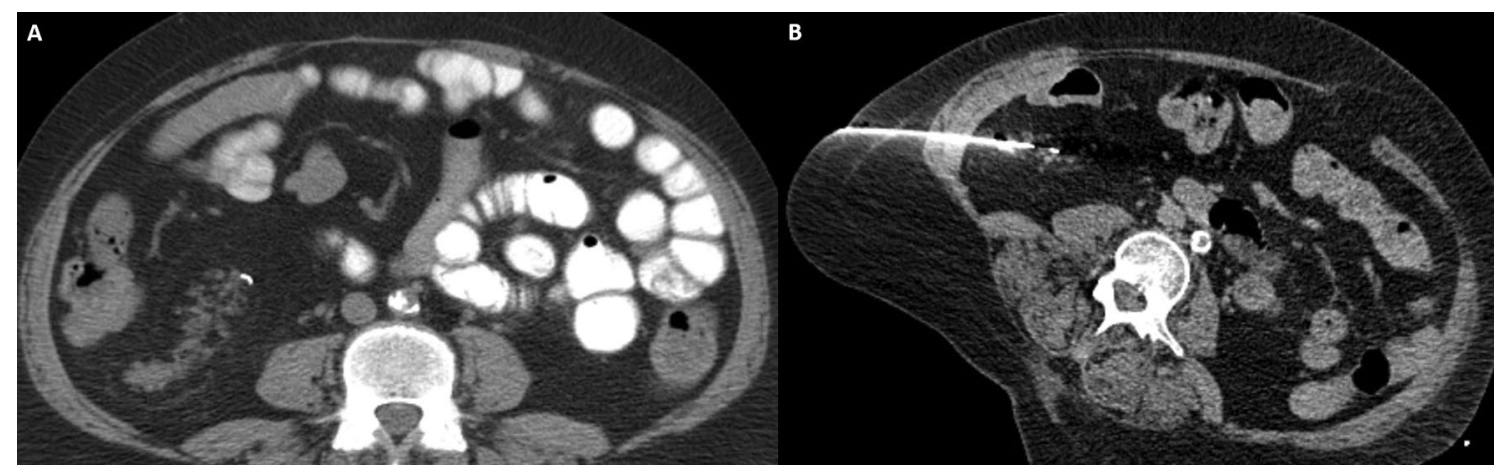

Fig. 6 Axial CT image without intravenous contrast A demonstrates a right lower quadrant pancreas transplant that was unable to be localized by ultrasound for biopsy. CT-guided biopsy image B dem- onstrates the patient in the oblique position with successful needle biopsy of the transplant pancreatic tail

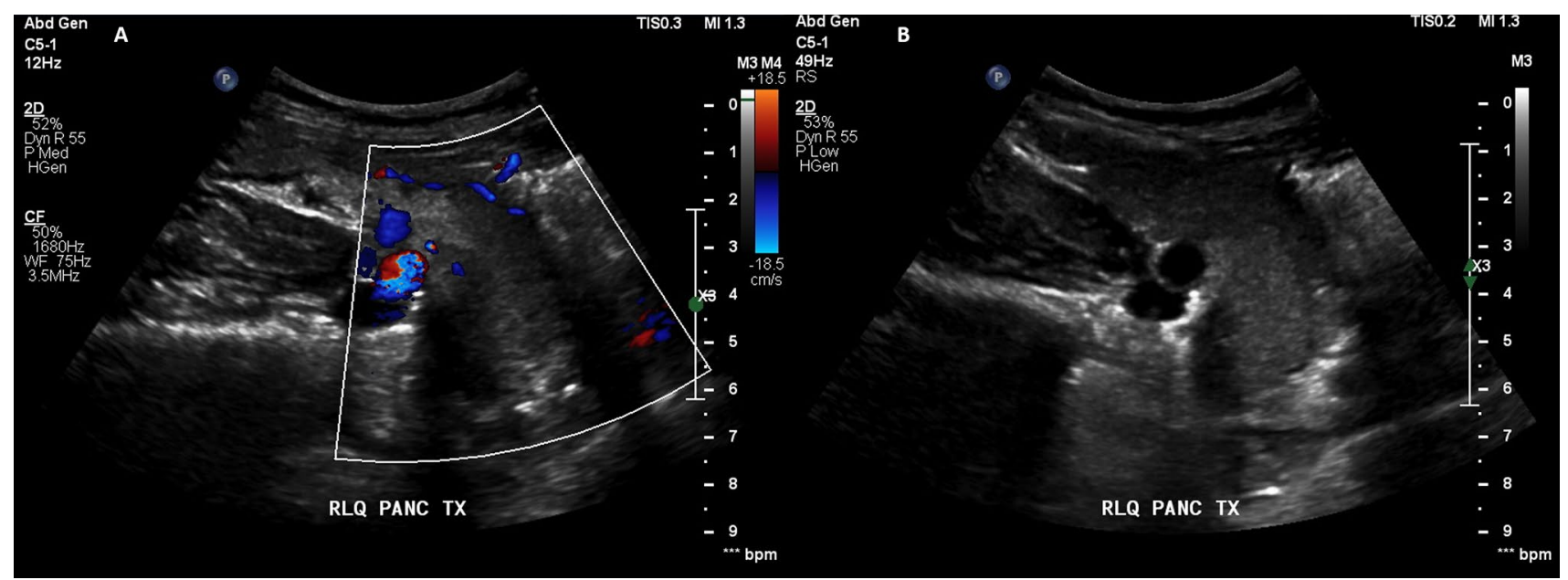

Fig. 7 Ultrasound images with (A) and without $(\mathbf{B})$ color Doppler demonstrate a normal-appearing transplant pancreas in the right lower quadrant with successful localization of the vascular pedicle

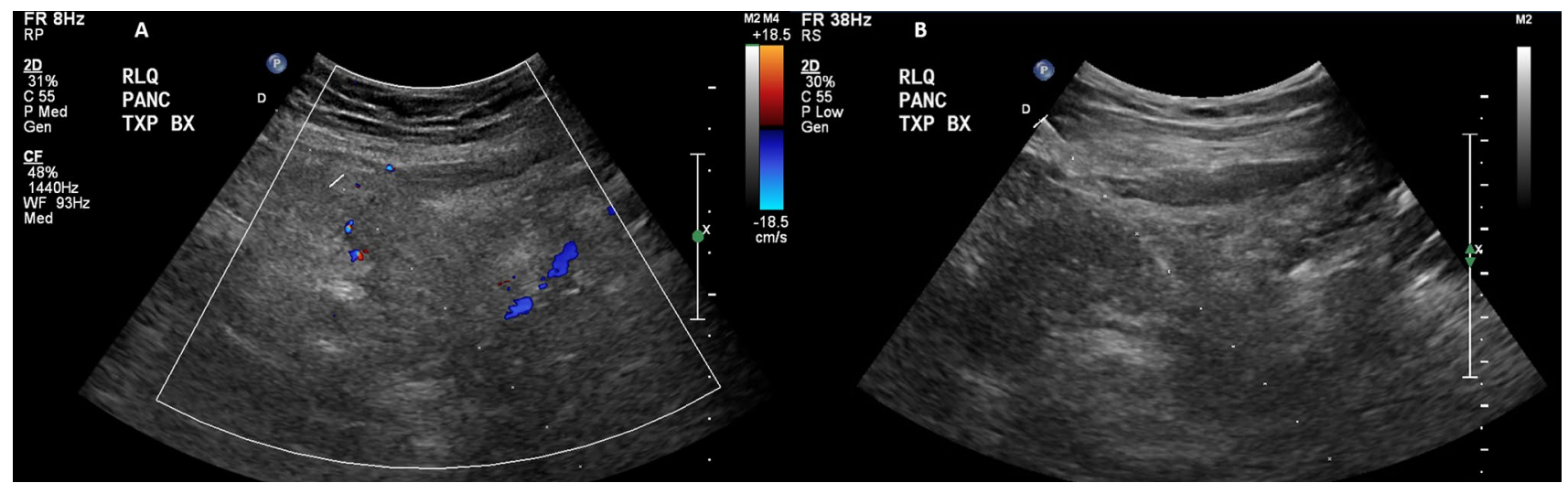

Fig. 8 Ultrasound with color Doppler image A demonstrates localization of a right lower quadrant pancreatic transplant for biopsy with successful identification of the vascular pedicle. Ultrasound-guided biopsy image B demonstrates successful advancement of the biopsy needle into the pancreatic transplant 
performed by non-radiologists, the diagnostic adequacy of samples ranged from 85 to $88 \%$, whereas a retrospective study evaluating yield of biopsies performed by radiologists found a diagnostic adequacy rate of over 96\% [21-23].

As with native pancreatic biopsies, radiologists may be uncertain and concerned about the potential complications that may arise following a pancreatic transplant biopsy. Overall, the rate of post-biopsy complications ranges from 1 to $3 \%$ and the most common complication is bleeding [21-23]. Other reported complications include pancreatitis, pancreatic fistula, pancreatic leak, gross hematuria (for a transplant anastomosed to the urinary bladder), severe pain, and non-targeted biopsy. Many of these are self-limited and do not require treatment, but some cases of bleeding and pain may require overnight hospitalization and/or intervention. Following pancreatic transplant biopsies, patients are typically observed in the postprocedural recovery area for $2-3 \mathrm{~h}$ to monitor for signs and symptoms of bleeding and to ensure that their pain is under control.

\section{Percutaneous drainage in pancreatitis}

\section{Introduction}

Acute pancreatitis is a common acute inflammatory process of the pancreas and has a range of severity and complications. While most episodes of acute pancreatitis are mild and will resolve within a short time period of approximately 1 week, severe pancreatitis occurs in 15-20\% of patients and takes a prolonged, complex clinical course that often includes the development of pancreatic and peripancreatic collections [24-27]. The interventional approach to management of pancreatitis and local complications has evolved over the past several decades. While surgical debridement was once considered the standard therapy for symptomatic or infected collections, and minimally invasive interventions, including percutaneous drainage, have now become the preferred treatment and offer the benefits of minimizing morbidity and avoiding the poor outcomes associated with invasive surgery $[25,28]$.

\section{Types of acute pancreatitis}

The management of pancreatitis requires a multidisciplinary team, which includes the radiology proceduralist. Appropriate interventional management by the proceduralist requires knowledge and recognition of the classifications of pancreatitis, associated fluid collections, and the imaging features of each. The 2012 revised Atlanta classification (RAC) is an international consensus that defines the clinical and radiologic criteria for the diagnosis of acute pancreatitis and differentiates the two types of acute pancreatitis into interstitial edematous pancreatitis and necrotizing pancreatitis. The RAC also provides objective terminology to describe the morphology of pancreatic and peripancreatic collections [29].

Interstitial edematous pancreatitis (IEP) is inflammation of the pancreas without necrosis. The imaging findings of IEP are diffuse or localized pancreatic enlargement with peripancreatic edema and possibly peripancreatic fluid. The parenchyma enhances relatively homogeneously on contrast-enhanced CT and MRI. Necrotizing pancreatitis (NP) is pancreatic inflammation with necrosis of the parenchyma, peripancreatic tissues, or both. Early in the disease time course, the enhancement pattern of NP is often patchy and heterogeneous, sometimes indistinguishable from IEP. A more well-demarcated area of non-enhancing parenchyma will become evident later in the disease, indicating parenchymal necrosis. Peripancreatic necrosis is characterized by peripancreatic collections containing both fluid and heterogeneous and non-fluid components, consistent with necrotic tissue (Fig. 9) [30, 31].

\section{Pancreatic and peripancreatic collections}

Pancreatic and peripancreatic collections are local complications identified and monitored by imaging, most commonly with Contrast-enhanced CT (CECT) or MRI [26, 27]. These collections are classified on the basis of symptom duration and designated as acute if $<4$ weeks after onset and delayed if $>4$ weeks after onset. Classification of the collections also depends on the type of ongoing pancreatitis-IEP or NP.

Fluid collections occurring with IEP are termed Acute peripancreatic fluid collections (APFCs) and pseudocysts. APFCs occur during the first 4 weeks in IEP. These fluid collections will appear as homogeneous fluid density and lack a defined wall. No intra-pancreatic extension is present. APFCs will usually remain sterile and resolve without drainage [29, 30, 32]. Pseudocysts occur after 4 weeks in IEP and are typically peripancreatic. Pseudocysts have a defined wall/capsule and contain no non-liquid component (Fig. 10) $[29,30]$.

In NP, collections are termed Acute necrotic collections (ANC) within the first 4 weeks and walled-off necrosis (WON) after the first 4 weeks. ANCs will be heterogeneous and contain variable amounts of liquid and non-liquefied material, such as solid appearing or fatty components, consistent with necrotic debris (Fig. 11). In the early phase of pancreatitis, distinguishing between necrotic and nonnecrotic collections can be difficult, but often becomes clear by the 2 nd week at which time either CECT or MRI can be repeated [29]. MRI can better delineate necrotic debris within collections that is unrecognized by CT (Fig. 12) [33]. 


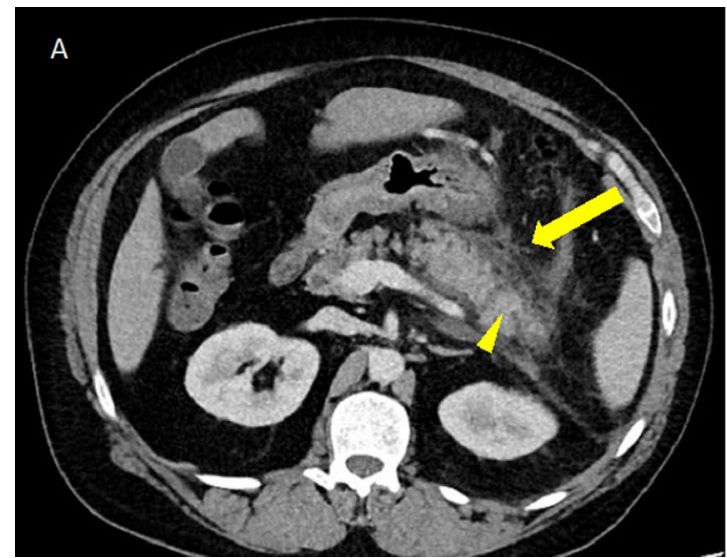

Fig. 9 Acute interstitial edematous pancreatitis and necrotizing pancreatitis in two patients. A Axial IV contrast-enhanced CT in a patient with acute IEP showing peripancreatic stranding and fluid (arrow) and mildly heterogeneous enhancement of the pancreas (arrowhead).

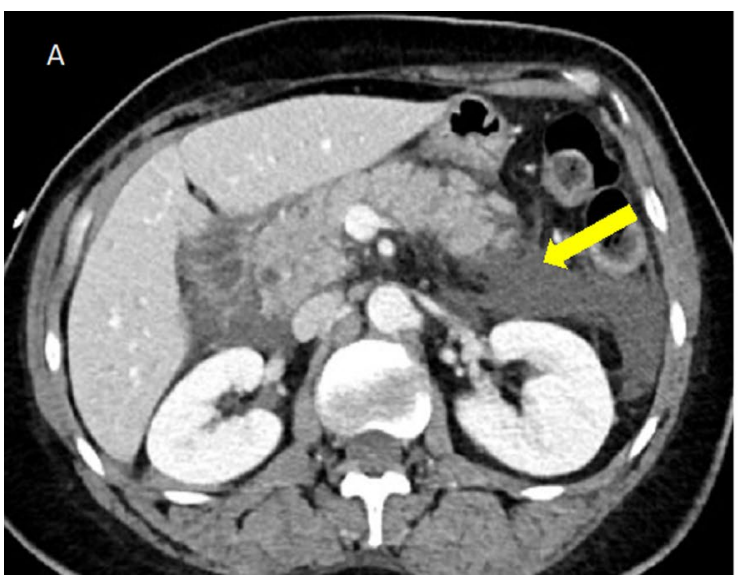

Fig. 10 Peripancreatic collections in interstitial edematous pancreatitis. A Axial IV contrast-enhanced CT in a patient with acute IEP and simple, homogeneous fluid density peripancreatic collections (arrow). B Axial IV contrast-enhanced CT in a patient with a history

\section{Infection}

Infection in pancreatitis can be suspected based on clinical signs, such as fever or bacteremia, or if gas is seen within a collection on imaging (Fig. 13) [29]. Wall enhancement is not a reliable imaging finding for infection and can be seen in sterile pseudocysts and WON [30]. While any collection in pancreatitis can be sterile or infected, necrosis becomes infected more frequently and carries a mortality rate of up to $30 \%$ [25].

\section{Role of percutaneous intervention in pancreatitis}

Historically, open surgical debridement was the mainstay therapy for infected necrosis and symptomatic sterile

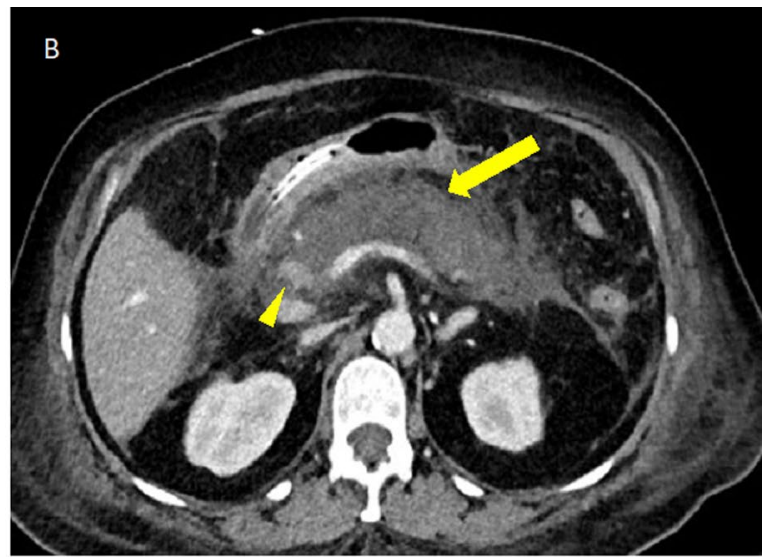

B Axial IV contrast-enhanced CT in a patient with acute NP showing a large area of non-enhancement of the pancreas and peripancreatic stranding (arrow). A small area of enhancing pancreatic parenchyma is seen in the pancreatic head (arrowhead)

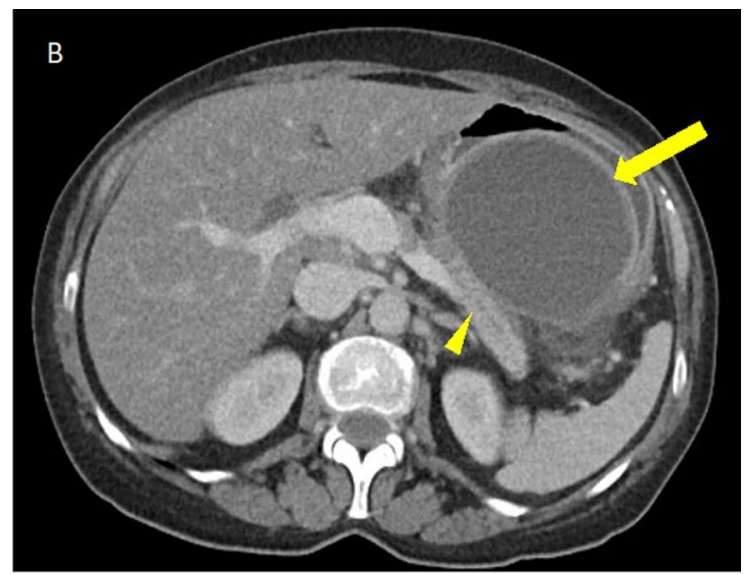

of IEP beginning 8 weeks ago showing a homogeneous fluid density peripancreatic collection (arrow) abutting the pancreatic body (arrowhead) with an enhancing capsule/rim, compatible with a pseudocyst

necrosis, but is associated with high rates of complication and mortality ranging 11-39\% [34-36]. The treatment paradigm has evolved, and the traditional surgical approach has been replaced by less invasive measures, including percutaneous drainage. As minimally invasive treatment modalities for the management of pancreatitis have become more widely available, consensus practice guidelines now include recommendations regarding clinical indications for intervention, intervention strategies, and timing of intervention [25, $27,28]$. 


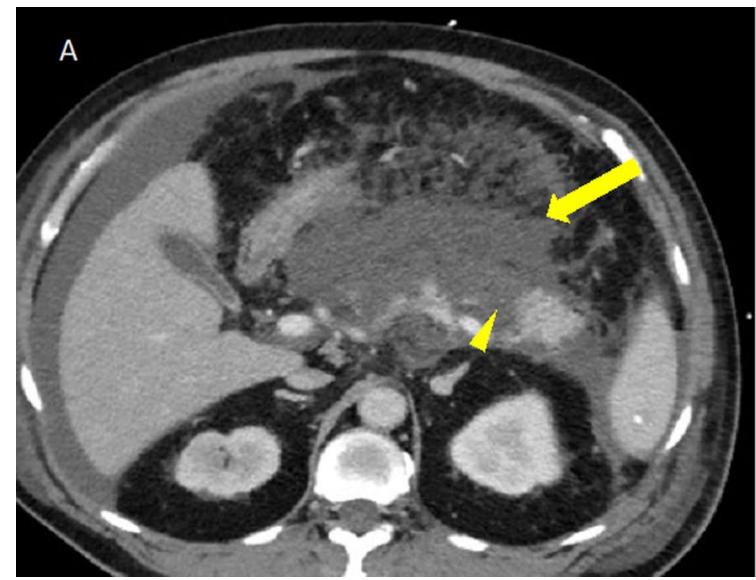

Fig. 11 Peripancreatic and pancreatic collections in necrotizing pancreatitis. A Axial IV contrast-enhanced CT in a patient with acute NP and ANCs involving the pancreatic parenchyma (arrowhead) and the peripancreatic tissues (arrow). B Axial IV contrast-enhanced CT in a

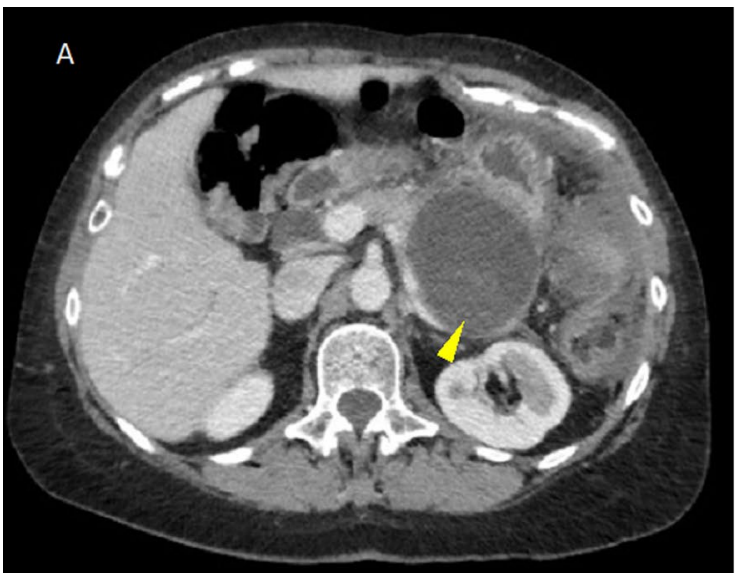

Fig. 12 Necrotic debris in walled-off necrosis. A Axial IV contrastenhanced CT in a patient with WON involving the pancreatic body and tail with subtle heterogeneous density in the collection indicating necrotic debris (arrowhead). B Axial T2W sequence in the same

\section{Clinical indications for drainage}

\section{Necrotizing pancreatitis}

The Working Group International Association of Pancreatology/American Pancreatic Association (IAP/APA) Acute Pancreatitis Guidelines define the clinical indications for percutaneous, endoscopic, or surgical drainage of collections in necrotizing pancreatitis. Indications include (1) suspected or confirmed infected necrosis with clinical deterioration and (2) ongoing organ failure for several weeks after the onset of acute pancreatitis, in the absence of infection. Other clinical indications for drainage in necrotizing pancreatitis include

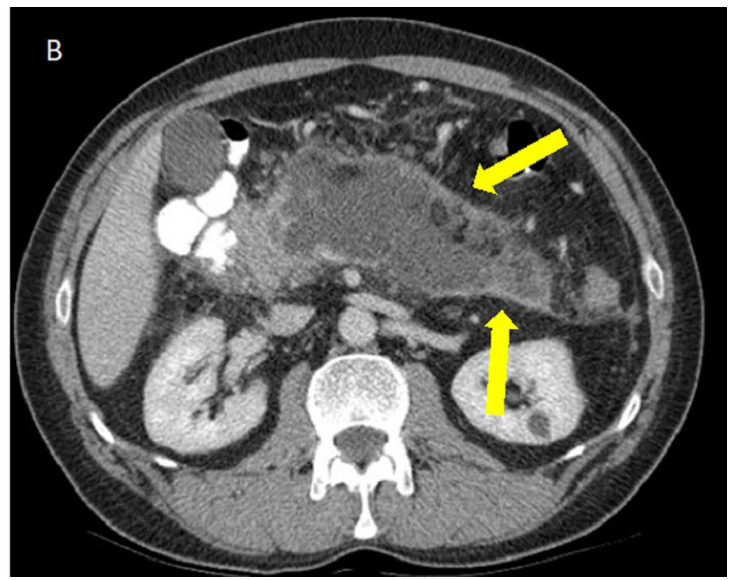

patient with NP and a large area of WON occupying the pancreatic body and tail with an enhancing capsule (arrows). Note the heterogeneous appearance of the collections in NP which contains fluid density intermixed with fat density

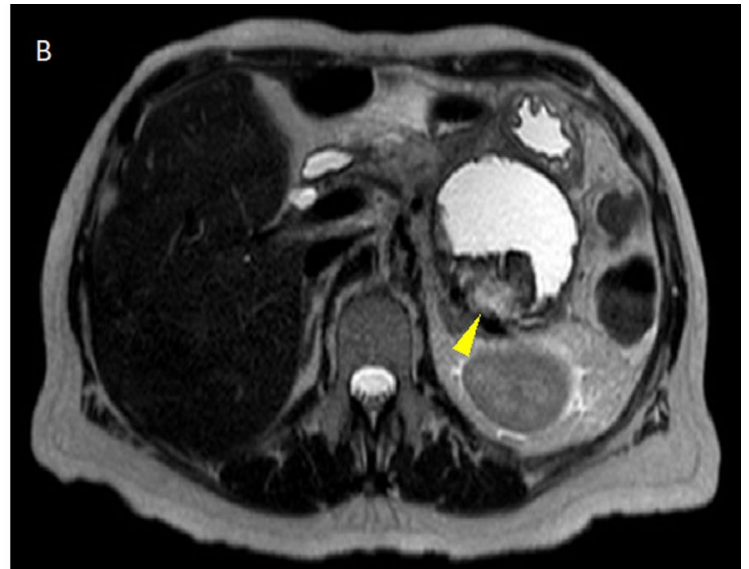

patient obtained the next day showing comparatively more obvious necrotic debris in the same WON as indicated by heterogeneous signal intensity (arrowhead)

(1) mechanical gastric, intestinal, or biliary obstruction, (2) persistent "unwellness," including pain, nausea, vomiting, or nutritional failure, and (3) symptomatic disconnected duct syndrome [25-28, 37]. Disconnected duct syndrome is characterized by full transection of the pancreatic duct by necrosis resulting in symptomatic fluid collections due to leaking pancreatic fluid [37].

Sterile necrosis without clinical deterioration, organ failure, or persistent "unwellness" does not require intervention. A prospective observational cohort study of 639 patients with necrotizing pancreatitis reported that $62 \%$ of patients were successfully treated with conservative management only with a relatively low mortality rate of 7\% [38]. 


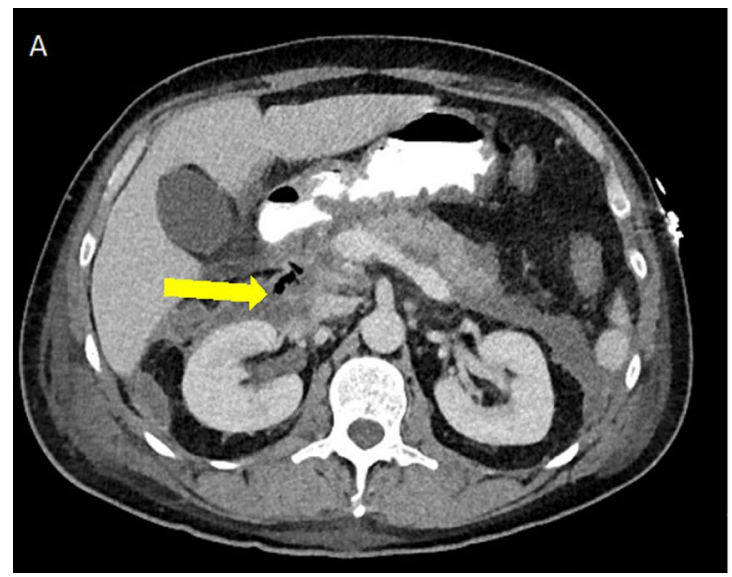

Fig. 13 Gas within necrotizing pancreatitis collections due to infection. A Axial PO and IV contrast-enhanced CT showing a patient with NP with a small amount of gas in WON near the pancreatic head (arrow). No extraluminal contrast was seen to indicate bowel perforation. This patient required percutaneous drainage due to infection.

\section{Interstitial edematous pancreatitis}

Drainage of fluid collections associated with IEP is usually not necessary, even when large APFC and pseudocysts are present, as these collections most commonly resolve without intervention [26, 32]. Rare exceptions to this principle include uncommon complications of pseudocysts, such as obstruction of the biliary or intestinal tract or prolonged symptoms, such as pain and nausea, for which drainage is indicated (Fig. 14) [27].
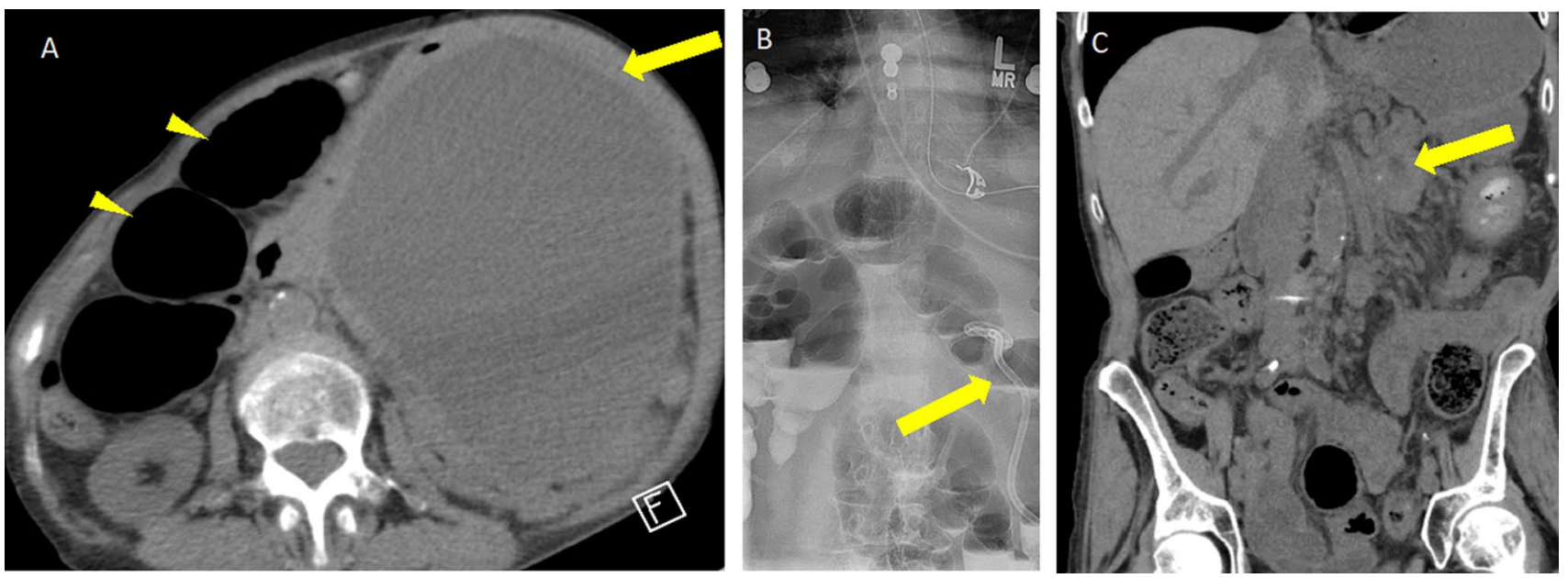

Fig. 14 Pancreatic pseudocyst causing small bowel obstruction and requiring therapeutic percutaneous drainage. A Axial non-contrast $\mathrm{CT}$ in a patient with a large pseudocyst (arrow) in the left abdomen and multiple dilated bowel loops in the right abdomen (arrowheads). B Abdominal radiograph in standing position following placement

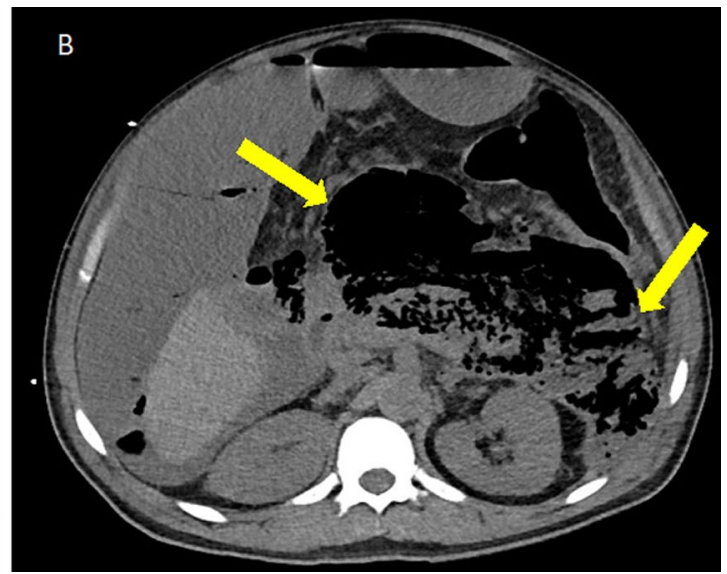

B Axial non-contrast CT shows extensive gas within a large infected ANC replacing the pancreas. Percutaneous and endoscopic drainage were pursued in this patient, but ultimately surgical retroperitoneal debridement was required

\section{Intervention strategies}

Multiple published series have defined the role of percutaneous catheter drainage in necrotizing pancreatitis, both as definitive monotherapy and as adjunct therapy in combination with endoscopic intervention [36, 38-41]. The recommended interventional strategy is the "step-up" approach, which begins with either percutaneous or endoscopic drainage of infected necrosis. If no clinical improvement is evident $72 \mathrm{~h}$ after the initial drainage and other drainable collections are present, a second drainage is performed. If of percutaneous drain (arrow) into the pseudocyst and persistently dilated bowel loops containing enteric contrast. C Follow-up coronal non-contrast CT 2 months later after drain removal shows a small residual pseudocyst (arrow) and resolved bowel obstruction 
additional drainage is not possible or if there is no clinical improvement after an additional $72 \mathrm{~h}$, the next step is endoscopic necrosectomy or Video-assisted retroperitoneal debridement (VARD). The primary objective behind this approach is to control the infected necrosis with the least invasive measures and to postpone or avoid more invasive surgery. The step-up approach was shown to be superior to open necrosectomy for infected necrosis in the landmark Dutch PANTER trial with lower rates of new-onset organ failure, new-onset diabetes, and incisional hernia in the step-up group [36]. Trials have reported that up to $51 \%$ of patients managed with the step-up approach were adequately treated with drainage alone and did not require the next step of necrosectomy [36, 40].

Generally, the endoscopic transluminal/transmural approach for drainage is preferred to avoid the risk of pancreaticocutaneous fistula; however, the percutaneous approach plays an important role. Deep retroperitoneal extension of collections into the paracolic gutters and pelvis is often inadequately drained endoscopically and require percutaneous drainage (Fig. 15) [25, 27, 37, 39]. Percutaneous drainage can also provide a route for bedside irrigation and clearance of necrotic material [37]. In patients with infection who are too unstable for endoscopic management, percutaneous drainage can be critical in providing a means for source control [25].

\section{Intervention timing}

If possible, delaying intervention for at least 4 weeks after the onset of acute pancreatitis is the standard recommendation by multiple published guidelines [25-28, 42]. These recommendations are primarily based on earlier literature when open necrosectomy was the treatment of choice for infected necrosis and performing surgery early (within $2-4$ weeks) was associated with poor outcomes [34, 43, 44]. Delaying intervention avoids the inherent pro-inflammatory effect of surgical intervention in the early course of pancreatitis, a vulnerable clinical period when the systemic inflammatory response is driving morbidity and mortality. Delaying intervention also allows for liquefaction and encapsulation of necrosis, which can further demarcate areas of necrosis from viable pancreatic tissue. In the early stages of necrosis, when the affected pancreas is an inflammatory mass, unintentional removal of viable pancreas has been postulated as a possible etiology for increased rates of pancreatic insufficiency following necrosectomy [36, 38].

More data are needed regarding the timing of percutaneous and endoscopic intervention. While infected necrosis is considered an event occurring later in the disease course ( $>4$ weeks), nearly $1 / 4$ of patients will develop infected necrosis earlier [45]. Some published series using a stepup approach have also supported the benefit of delaying intervention [38], but a more recent study comparing outcomes of a step-up approach initiated that before versus after 4 weeks showed no increase in complications, similar improvement in organ failure, and a relatively low mortality
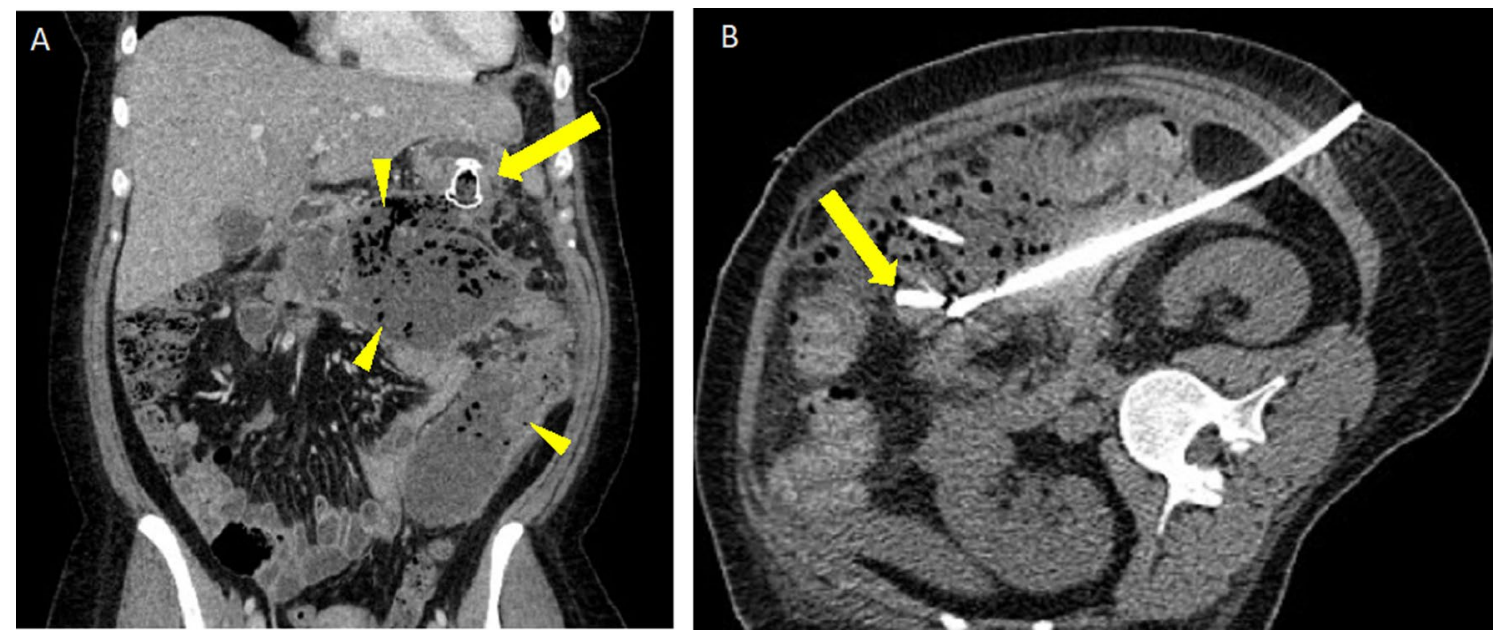

Fig. 15 Infected necrotizing pancreatitis requiring a combination of endoscopic and percutaneous drainage. A Coronal IV contrastenhanced CT showing large peripancreatic and pancreatic WON containing gas (arrowheads) and an endoscopically placed cystogastrostomy (arrow). B Axial CT during CT-guided drain placement via a left retroperitoneal approach with catheter in appropriate position within the collection (arrow). This approach was chosen to provide a portal for future surgical videoscopic assisted retroperitoneal debridement; however, the patient recovered without the need for surgery 
in the early intervention group [46]. Early intervention with percutaneous and/or endoscopic drainage may be appropriate in select scenarios, such as clinical deterioration due to infected necrosis [37].

\section{Image-guided aspiration}

While image-guided aspiration of fluid collections in pancreatitis is feasible and safe, its utility and relevance have diminished [28, 47-49]. In the past, when necrosectomy was the treatment of choice, documented infection by aspiration was considered immediate indication for surgical management. Infected necrosis is now often managed conservatively with antibiotics, reserving intervention for clinical deterioration. Further, false-negative rates of greater than $20 \%$ have been reported with fine-needle aspiration $[34,50]$. As such, published guidelines and consensus statements have recommended against routine aspiration for the diagnosis of infection [25, 27, 28]. Select clinical scenarios where aspiration might be appropriate include when fungal infection is suspected due to lack of clinical response to antibiotics [28].

\section{Percutaneous drainage in the post-operative pancreas}

\section{Introduction}

Despite modern advances in major pancreatic surgery, pancreatic fistula (e.g., leak) and abscess remain relatively common complications and are associated with increased mortality and morbidity, longer hospital stay, and increased costs [51-54]. Due to varying definitions of pancreatic fistula in the surgical literature and the overlap and grouping of terminology (e.g., fistula, leak, and abscess/infected fistula), a large range of occurrence rates have been reported, including up to $60 \%$ risk of fistula after distal pancreatectomy [55]. A now universally accepted definition and severity grading system of post-operative pancreatic fistula have been described by the International Study Group of Pancreatic Fistula. A clinically relevant fistula is defined as drain output of any measurable volume of fluid with an amylase level $>3$ times the upper limit of institutional normal serum amylase, associated with a clinically relevant development/condition, such as persistent prolonged drainage $>3$ weeks, infection, or related organ failure or death [51]. While the diagnosis is confirmed by drain criteria, any fluid collection or hemorrhage around the pancreatic anastomosis or resection suture line on imaging is concerning for fistula. Continuity of the collection with the pancreatic duct may also be visualized.

\section{Pancreatic fistula pathophysiology and risk factors}

Proposed mechanisms for pancreatic fistula differ based on the type of pancreatic surgery performed. Leakage of pancreatic sections from the pancreatic-intestinal anastomosis or from a traumatized surface of the gland is considered to be the sites of origin for fistula following Pancreaticoduodenectomy (PD) or Whipple procedure (Fig. 16). Several risk factors have been well established for PD fistula, including soft pancreatic texture, small ductal size, non-ductal adenocarcinoma pathology (such as duodenal or ampullary cancers), and intra-operative blood-loss greater than 1L [56]. Such risk factors have been implemented into a validated fistula risk score which influences surgical and management

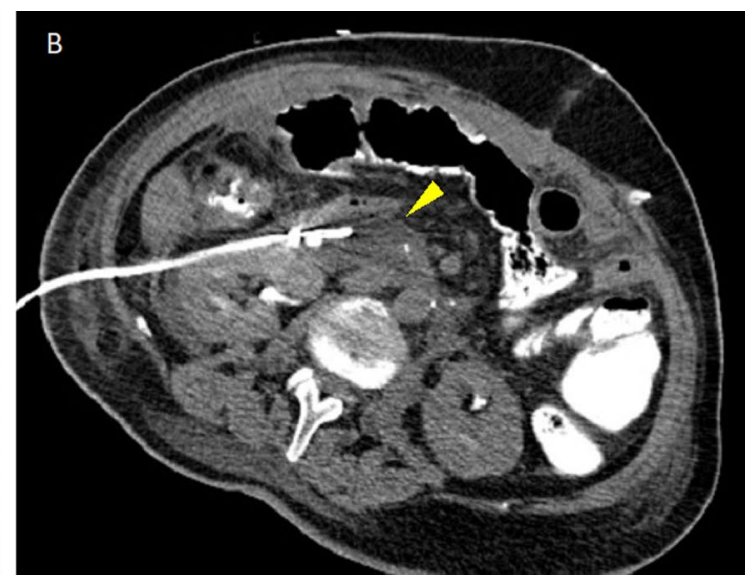

Follow-up axial CT was obtained after percutaneous drain placement via a right retroperitoneal approach showing the catheter in appropriate position and decreased size of the collection (arrowhead)
Fig. 16 Pancreatic fistula after Whipple for pancreatic adenocarcinoma. A Axial IV contrast-enhanced CT showing a surgical bed fluid collection (arrows) near the pancreaticojejunostomy (arrowhead). B 


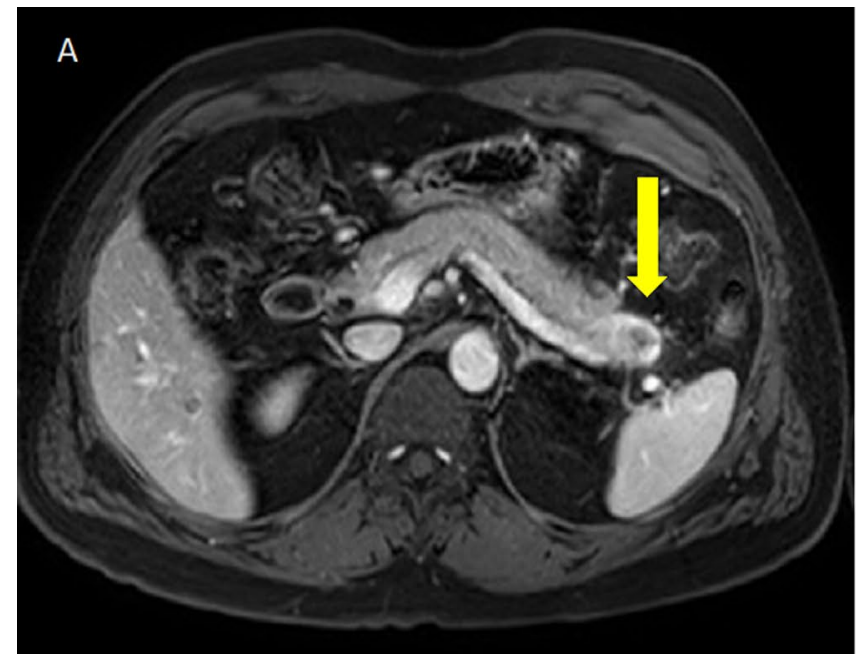

Fig. 17 Pancreatic fistula after distal pancreatectomy for pancreatic neuroendocrine tumor. A Axial MRI post-contrast T1W series in a patient with a hypervascular, solid mass in the pancreatic tail (arrow).

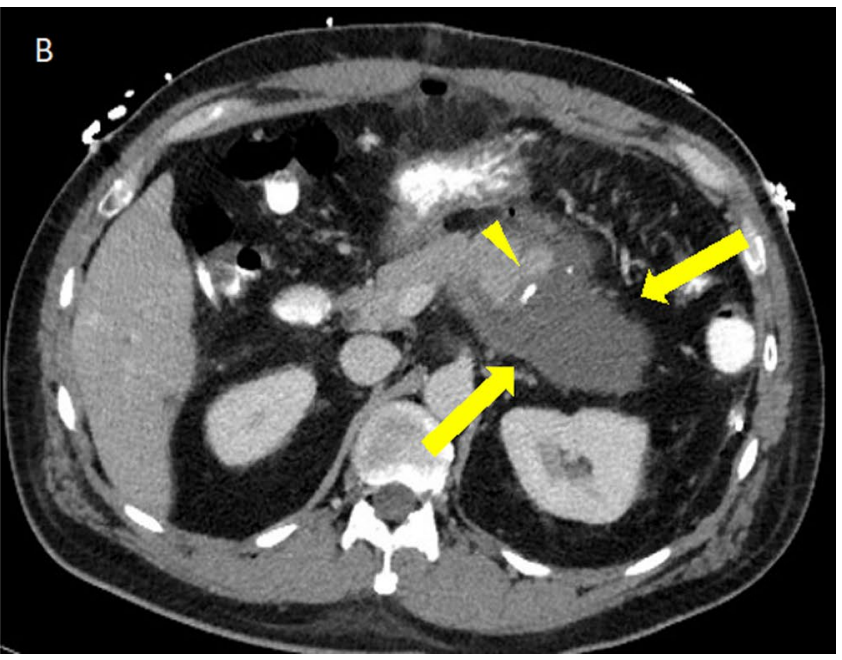

B Axial IV contrast-enhanced CT following distal pancreatectomy showing a fluid collection (arrows) in the surgical bed centered around the remnant pancreas staple line (arrowhead)

\section{Performing percutaneous drainage}

decisions, such as surgict
of drain removal [57].

Increased ductal pressure due to functional obstruction at the sphincter of Oddi complex has been hypothesized as the mechanism for pancreatic stump leakage following Distal pancreatectomy (DP) (Fig. 17) [58]. Lack of epidural anesthesia has been associated with an increased risk for DP fistula, which is thought to be related to reduce need for narcotic medications and resultant decreased pressure at the sphincter of Oddi. Several other risk factors for DP fistula have been reported, including age $<60$, obesity, neuroendocrine or non-malignant pathology, concurrent splenectomy, and vascular resection. These risk factors, however, did not accurately predict fistula formation when implemented into a risk scoring model [59].

\section{Intervention strategies}

Image-guided percutaneous drainage of post-operative pancreatic collections is technically safe and effective, and the prevalence of collections requiring drainage ranges up to approximately $20 \%$ [60, 61]. The utility of routine placement of surgical drains after pancreatic resection has been questioned with conflicting reports in the surgical literature; however, the presence or absence of surgical drains does not appear to reduce the need for percutaneous drainage of fistula in interventional radiology [62-65]. High technical success rates have been reported, ranging from 97 to $100 \%$, defined by drain placement within the collection $[60,61]$. Endoscopic methods for post-operative pancreatic collection drainage have also been successful [66, 67].

\section{Preparation and planning}

Preprocedural evaluation of the patient is a critical component to any successful percutaneous drainage. The Society of Interventional Radiology Consensus Guidelines for the Periprocedural Thrombotic and Bleeding Risk can be used as a general guide for risk assessment in percutaneous pancreatic drain placement, which is classified as a deep drainage with high bleeding risk [10]. INR and platelet count, as well as anticoagulation/antiplatelet holds should be considered in conjunction with a risk/benefit profile for the procedure and the patient's overall clinical status. Under physician supervision, moderate IV sedation can be provided by nursing staff for patient comfort and pain control during the procedure.

Imaging review is necessary to confirm the presence of a collection, to plan the approach for drainage, and for modality selection. CECT or MRI that includes an arterial phase should be obtained if there is a concern for a pseudoaneurysm masquerading as a fluid collection, which is a rare, but recognized complication in pancreatitis, often involving the splenic artery.

\section{Access routes}

Several potential access routes to peripancreatic and pancreatic collections exist, and the route should be chosen with consideration of the clinical scenario and risk of traversing other potentially avoidable structures, such as bowel and mesenteric vessels. When possible, a left retroperitoneal 

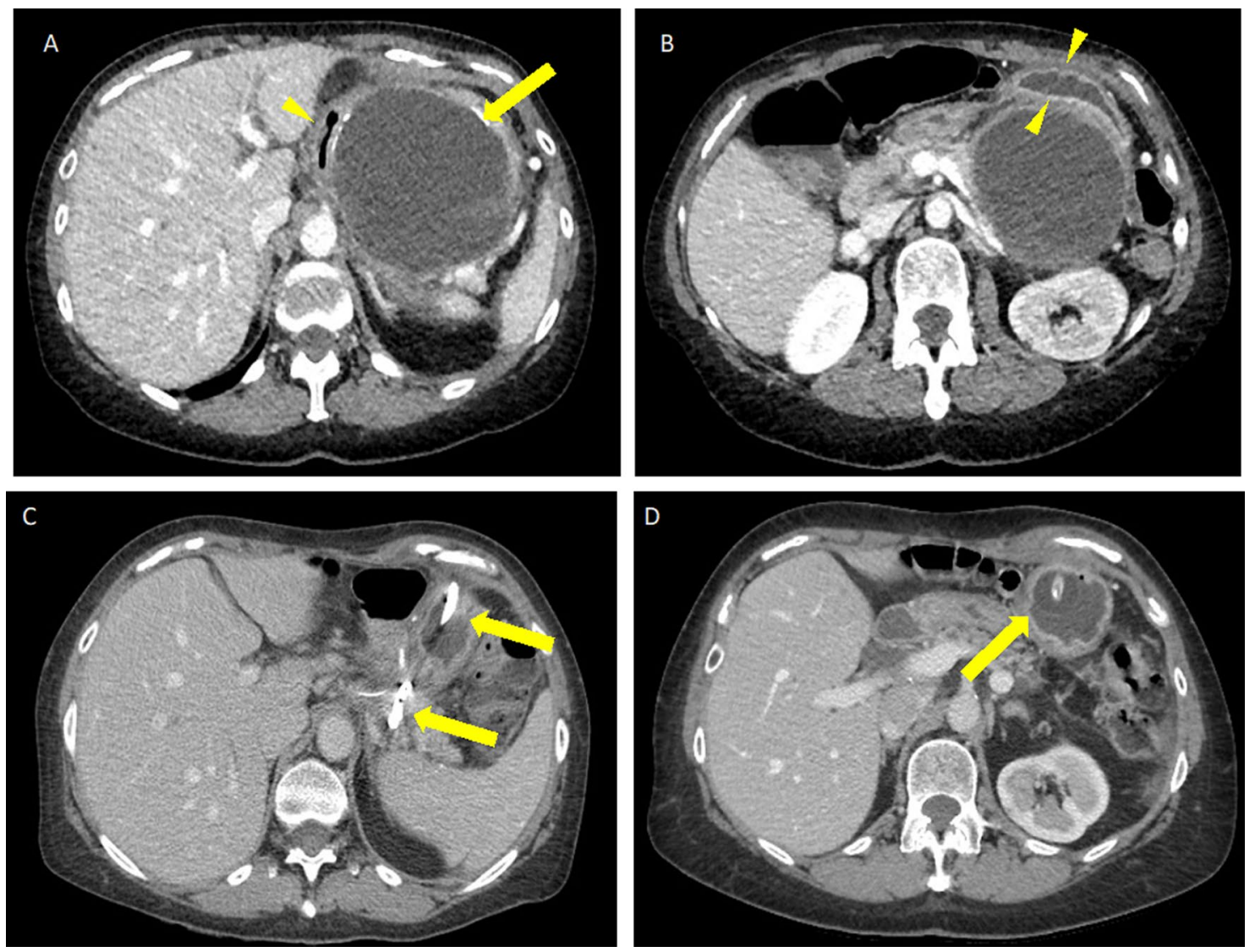

Fig. 18 Transgastric drainage of walled-off necrosis in a patient with Roux-en-Y gastric bypass. A Axial IV contrast-enhanced CT showing a large collection of WON (arrow) with mass effect on the gastric pouch (arrowhead) which was causing clinical symptoms of obstruction. B Axial IV contrast-enhanced CT shows that the gastric remnant (arrowheads) is anteriorly displaced by the WON. C Because the patient was nutritionally deficient and percutaneous gastrostomy

approach through the left anterior pararenal fascia should be chosen for percutaneous drainage in necrotizing pancreatitis. This approach minimizes the risk of peritoneal and bowel transgression and also creates a portal for future minimally invasive necrosectomy by tract endoscopy or VARD (Fig. 15) [37]. A transgastric approach may be considered if endoscopy is unavailable or if surgical anatomy, such as Roux-en-Y gastric bypass, limits endoscopic access or necessitates a percutaneous feeding tube (Fig. 18). Following PD, a collection in the deep surgical bed surrounding the pancreatic-intestinal anastomosis can be accessed through the right anterior pararenal fascia using hydrodissection for displacement of the colon [68]. Subphrenic collections are common in both the post-operative setting and pancreatitis

tube was going to be necessary for feeding in the future, a transgastric approach for drainage was performed to both drain the WON and establish a portal for gastrostomy placement. Axial IV contrastenhanced CT following drainage shows transgastric access by the catheter into the WON (arrows) which is now smaller. D Subsequently, the drain was removed and a gastrostomy tube was placed through the same tract (arrow)

and preferably drained via a subcostal approach to avoid pleural transgression and associated risks of fistula and empyema. If a subcostal approach is not available, selecting the most anterior and inferior intercostal access point and angling the catheter up into the collection is recommended (Fig. 19) [69].

\section{Image guidance}

The most commonly used modalities for image-guided deep drainages are ultrasound and CT, including CT fluoroscopy. Ultrasound offers the advantages of real-time visualization of the needle and catheter reaching the collection. The multiplanar capabilities of ultrasound are particularly useful in 

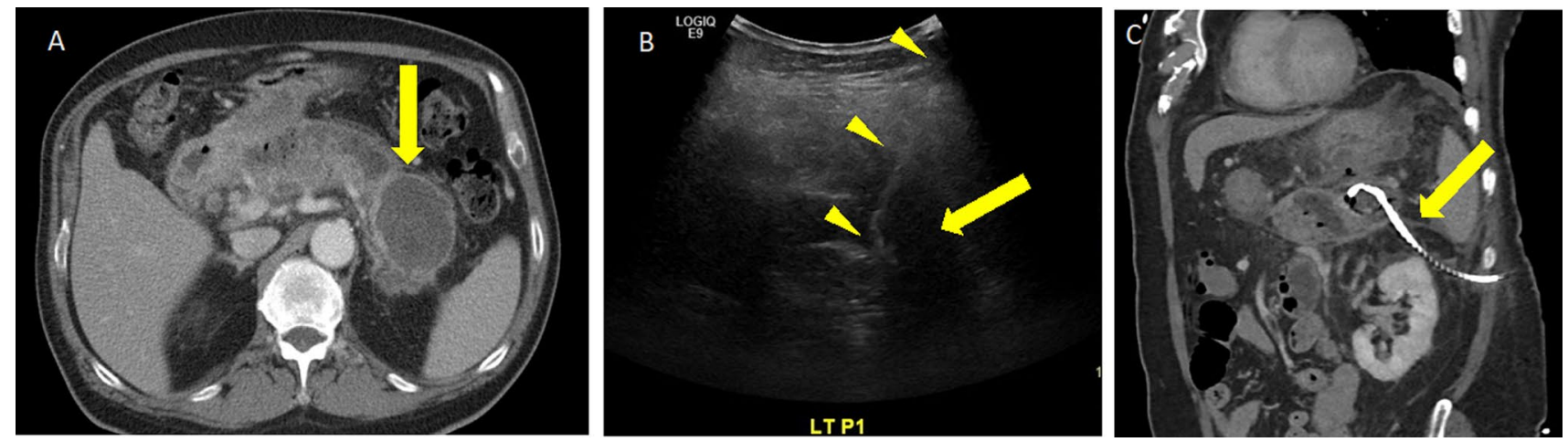

Fig. 19 Subcostal approach for percutaneous drainage of walled-off necrosis via ultrasound guidance. A Axial IV contrast-enhanced CT in a patient with NP and WON in the distal pancreatic body (arrow). B Ultrasound image of the left upper quadrant with the transducer angled superomedially toward the pancreas shows placement of the needle and guidewire (arrowheads) within the collection (arrow). C Oblique sagittal reformatted IV contrast-enhanced CT following percutaneous drainage shows the catheter (arrow) coursing inferior to the rib to reach the WON, minimizing the risk of pleural transgression subphrenic collections that require an oblique or angled route to avoid critical overlying structures in the axial plane. CT has higher spatial resolution and may be necessary for small and deeper collections, or when technical factors, such as body habitus, may limit the approach with US. CT gantry angulation can be a helpful tool for an angled trajectory to reach collections.

\section{Technique}

Placement of a percutaneous drainage catheter into a collection is achieved by use of the Seldinger technique or trocar technique. The Seldinger technique involves placing a hollow introducer needle percutaneously into the collection, inserting a guidewire to secure access, and then subsequent removal of the introducer needle. This is followed by sequential dilation of the tract over the guidewire, insertion of the catheter over a metal or plastic stiffener into the collection, and removal of the guidewire and stiffener. While this method requires more steps than the trocar technique, the advantage is the ability to precisely target collections with narrow windows. The trocar technique uses a catheter mounted on a sharp trocar which is directly inserted without a guidewire into the collection after superficial blunt dissection. Preceding the catheter insertion, placement of a guiding needle into the collection can provide an external reference for accurate placement of the catheter in tandem, so called the "tandem" trocar technique. The trocar technique allows the operator to quickly insert the catheter; however, this technique does not allow catheter repositioning after the first pass [70-72]. An additional modification to the trocar technique, the curved trocar technique, involves bending the metal trocar to allow intermittent visualization and redirection/adjustment of the catheter under CT fluoroscopy prior to being positioned within the collection [73].

A large range catheter size has been reported for use in pancreatic collections, and selection of the catheter size will vary depending on the contents of the collection. Generally, pancreatic collections require larger catheters for drainage due to viscous contents, possibly related to effects of amylase and lipase on fat necrosis. Small catheters (8-12 Fr) can be upsized to larger catheters (14-30 Fr) if solid necrotic components are present $[61,70]$. Multiple catheters may be required for adequate drainage of complex collections. Breaking up loculations within collections can be performed by manipulation of a wire or metal stiffener during the initial drain placement [74]. Continuous or intermittent large volume irrigation with normal saline may also facilitate the drainage of complex collections when multiple drains are present. Irrigation volume may range from 0.5 to $1.5 \mathrm{~L} /$ drain/day depending on the collection size [71]. 

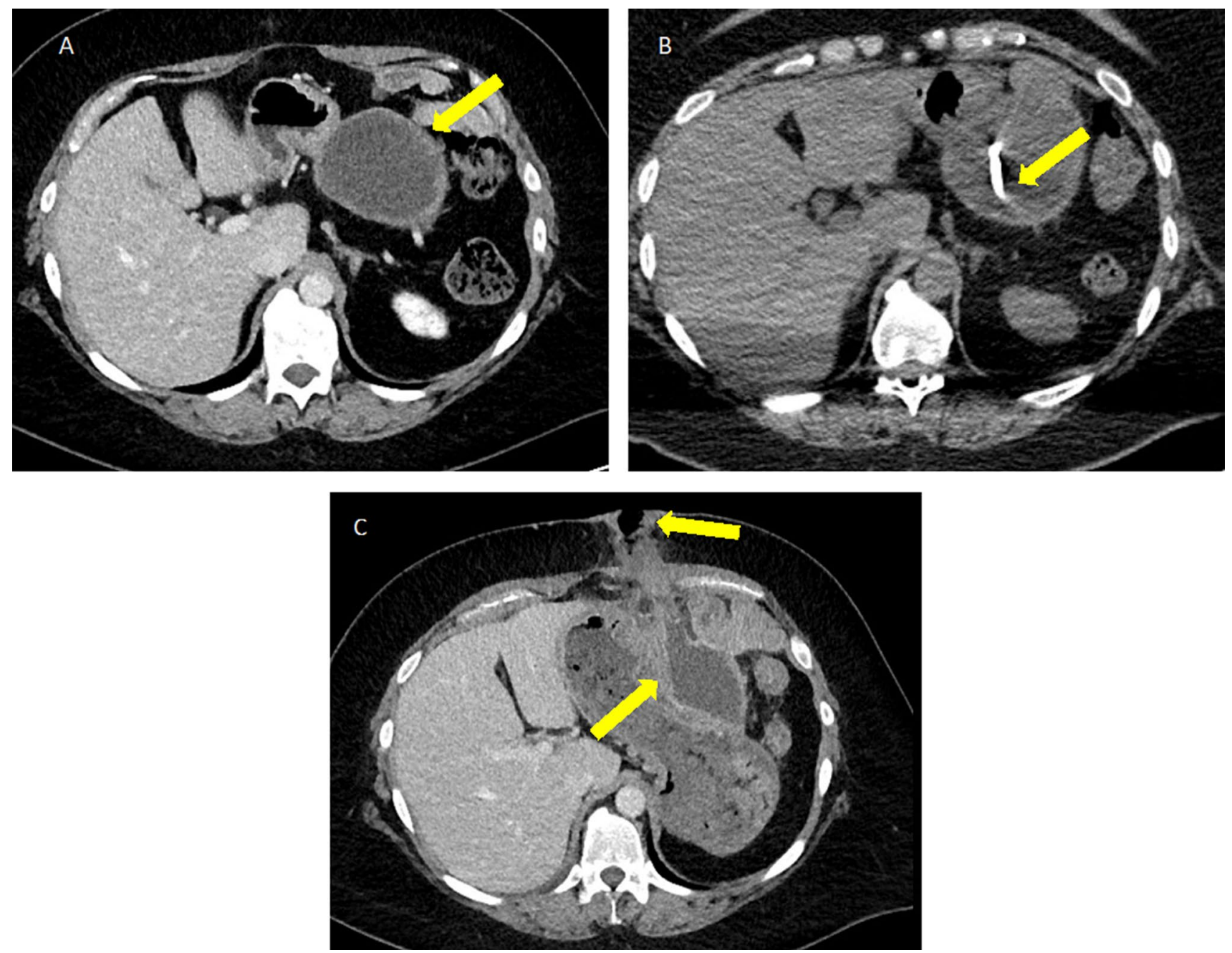

Fig. 20 Pancreaticocutaneous fistula as a complication of percutaneous drainage. A Axial IV contrast-enhanced CT showing a patient with peripancreatic WON (arrow). B Axial non-contrast CT shows the percutaneous drainage catheter within the WON (arrow). C Following drain removal, the patient complained of fluid drainage at the skin through the tract of the prior drain. Axial IV contrast-enhanced CT shows persistence of the collection after drainage, now extending along the prior drain tract into the ventral abdominal wall reaching the superficial body wall (arrows)

\section{Drain management}

Frequent and early drain monitoring on daily rounds ensures appropriate catheter function and position by assessing drain output and flushing the catheters with normal saline. If concern is raised for drain malfunction due to sudden decrease in output or failed clinical improvement, repeated crosssectional imaging or injection under fluoroscopy can be performed. Intracavitary fibrinolytic agents, such as tissue plasminogen activator, can be instilled within the catheter to degrade fibrin bands in viscous collections and facilitate drainage [75]. When catheter output is less than $20 \mathrm{cc} /$ day and the patient's condition improves, drain removal can be considered after discussion with the multidisciplinary care team. Updated cross-sectional imaging can be obtained to ensure resolution of the collection. 
Fig. 21 Percutaneous drainage of a pancreatic fistula after distal pancreatectomy complicated by drainage catheter fracture. A Coronal IV contrast-enhanced CT showing a left upper quadrant fluid collection (arrow) adjacent to the pancreatic remnant staple line (arrowhead) consistent with pancreatic fistula. B-D Axial IV contrastenhanced CT and fluoroscopic images obtained 15 days after drain placement shows fractured catheter fragments (arrow) which were subsequently retrieved in interventional radiology under fluoroscopy by loop snare
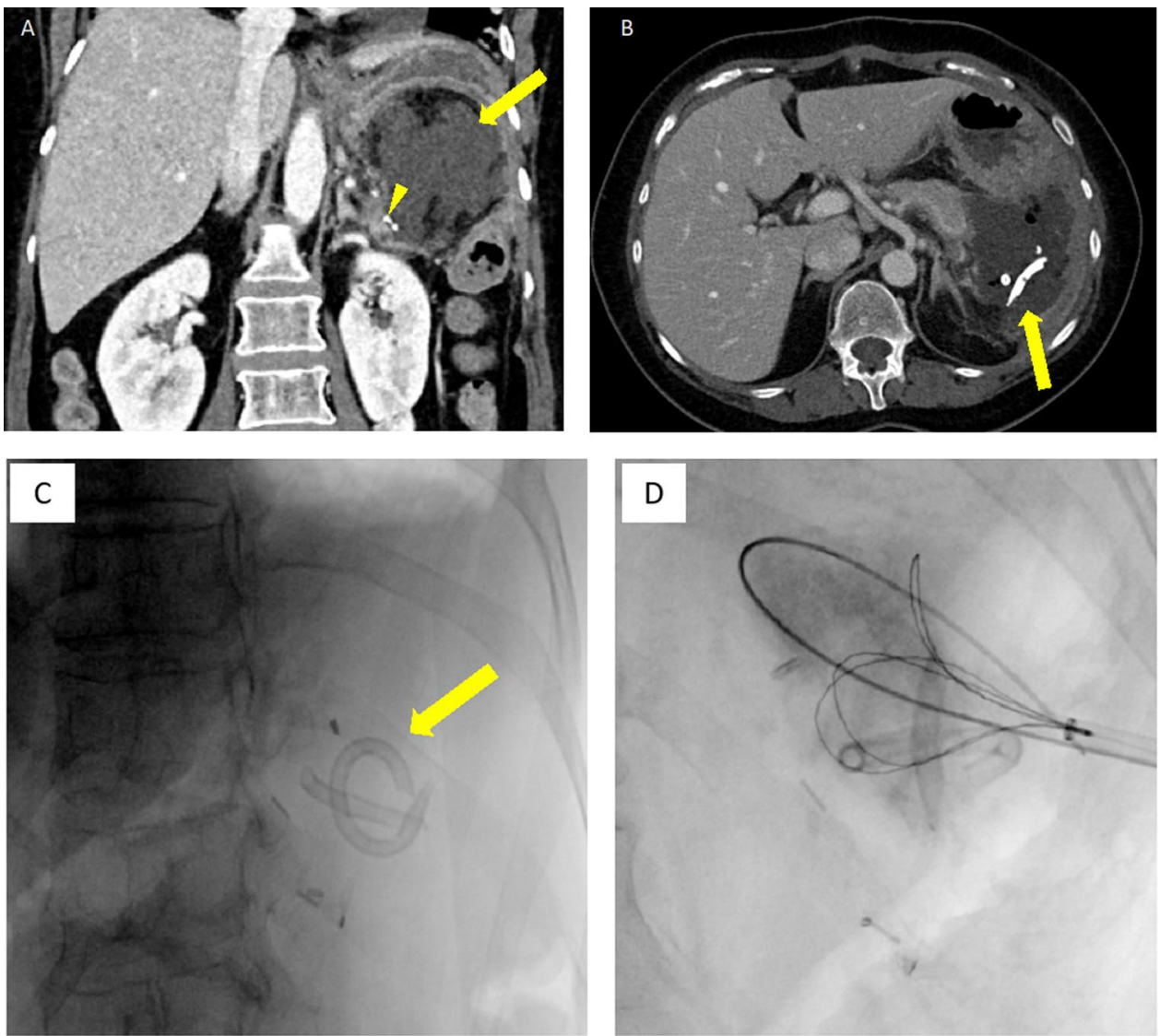

\section{Complications}

Major complications in percutaneous drainage, such as uncontrolled bleeding and organ injury, are rare with reported rates of up to $4 \%$ [41, 61, 71]. Pancreaticocutaneous fistula in pancreatitis has been reported in up to $32 \%$; however, the risk of fistula decreases when dual modality drainage is pursued with combined endoscopic and percutaneous catheters (Fig. 20) [40, 76]. An unusual complication observed in the author's practice is breakdown/fracture of the drainage catheter by a collection associated with a pancreatic duct fistula, presumed to be related to the enzymatic contents of the collection (Fig. 21).

\section{Conclusion}

As illustrated above, the management of patients with abnormalities of the pancreas necessitates a multidisciplinary approach. Radiologists should not only be familiar with pancreatic imaging but also the potential advantages and disadvantages to percutaneous procedures performed on the pancreas. An interdisciplinary approach to the management of patients with pancreatitis allows for optimal patient selection and management, and radiologists should be familiar with guidelines and evidence surrounding management of percutaneous drains in peripancreatic fluid collections.

\section{Declarations}

Research involving human and animal rights This article does not contain any studies with human or animal subjects performed by any of the authors.

\section{References}

1. Sundaram M, Wolverson MK, Heiberg E, Pilla T, Vas WG, Shields JB. Utility of CT-guided abdominal aspiration procedures. AJR Am J Roentgenol. 1982;139(6):1111-5. doi: https://doi.org/ 10.2214/ajr.139.6.1111.

2. Binmoeller KF, Thul R, Rathod V, Henke P, Brand B, Jabusch $\mathrm{HC}$, et al. Endoscopic ultrasound-guided, 18-gauge, fine needle aspiration biopsy of the pancreas using a $2.8 \mathrm{~mm}$ channel convex array echoendoscope. Gastrointest Endosc. 1998;47(2):121-7. doi: https://doi.org/10.1016/s0016-5107(98)70343-8.

3. Kogure H, Sato T, Nakai Y, Ishigaki K, Hakuta R, Saito K, et al. Endoscopic management of pancreatic diseases in patients with surgically altered anatomy: clinical outcomes of combination of 
double-balloon endoscopy- and endoscopic ultrasound-guided interventions. Dig Endosc. 2021;33(3):441-50. doi: https://doi. org/10.1111/den.13746.

4. Tikkakoski T, Siniluoto T, Päivänsalo M, Typpö T, Turunen J, Apaja-Sarkkinen M. Diagnostic accuracy of ultrasound-guided fine-needle pancreatic biopsy. Rofo. 1992;156(2):178-81. doi: https://doi.org/10.1055/s-2008-1032860.

5. Woolf KM, Liang H, Sletten ZJ, Russell DK, Bonfiglio TA, Zhou $Z$. False-negative rate of endoscopic ultrasound-guided fine-needle aspiration for pancreatic solid and cystic lesions with matched surgical resections as the gold standard: one institution's experience. Cancer Cytopathol. 2013;121(8):449-58. doi: https://doi. org/10.1002/cncy.21299.

6. Fisher L, Segarajasingam DS, Stewart C, Deboer WB, Yusoff IF. Endoscopic ultrasound guided fine needle aspiration of solid pancreatic lesions: Performance and outcomes. J Gastroenterol Hepatol. 2009;24(1):90-6. doi: https://doi.org/10.1111/j.14401746.2008.05569.x.

7. Eloubeidi MA, Jhala D, Chhieng DC, Chen VK, Eltoum I, Vickers $\mathrm{S}$, et al. Yield of endoscopic ultrasound-guided fine-needle aspiration biopsy in patients with suspected pancreatic carcinoma. Cancer. 2003;99(5):285-92. doi: https://doi.org/10.1002/cncr.11643.

8. Shin HJ, Lahoti S, Sneige N. Endoscopic ultrasound-guided fineneedle aspiration in 179 cases: the M. D. Anderson Cancer Center experience. Cancer. 2002;96(3):174-80. doi: https://doi.org/10. 1002/cncr.10614.

9. Bhatti I, Ojo D, Dennison AR, Rees Y, Elabassy M, Garcea G. Percutaneous Pancreatic Biopsies-Still an Effective Method for Histologic Confirmation of Malignancy. Surg Laparosc Endosc Percutan Tech. 2016;26(4):334-7. doi: https://doi.org/10.1097/sle. 0000000000000288

10. Patel IJ, Rahim S, Davidson JC, Hanks SE, Tam AL, Walker TG, et al. Society of Interventional Radiology Consensus Guidelines for the Periprocedural Management of Thrombotic and Bleeding Risk in Patients Undergoing Percutaneous Image-Guided Interventions-Part II: Recommendations: Endorsed by the Canadian Association for Interventional Radiology and the Cardiovascular and Interventional Radiological Society of Europe. J Vasc Interv Radiol. 2019;30(8):1168-84.e1. doi: https://doi.org/10.1016/j.jvir. 2019.04.017.

11. Stella SF, Van Borsel M, Markose G, Nair SB. Image-Guided Percutaneous Biopsy for Pancreatic Lesions: 10-Year Experience in a Tertiary Cancer Center. Can Assoc Radiol J. 2019;70(2):199203. doi: https://doi.org/10.1016/j.carj.2018.10.014.

12. Brandt KR, Charboneau JW, Stephens DH, Welch TJ, Goellner JR. CT- and US-guided biopsy of the pancreas. Radiology. 1993;187(1):99-104. doi: https://doi.org/10.1148/radiology.187.1. 8451443

13. Paulsen SD, Nghiem HV, Negussie E, Higgins EJ, Caoili EM, Francis IR. Evaluation of imaging-guided core biopsy of pancreatic masses. AJR Am J Roentgenol. 2006;187(3):769-72. doi: https://doi.org/10.2214/ajr.05.0366.

14. Tyng CJ, Almeida MF, Barbosa PN, Bitencourt AG, Berg JA, Maciel MS, et al. Computed tomography-guided percutaneous core needle biopsy in pancreatic tumor diagnosis. World J Gastroenterol. 2015;21(12):3579-86. doi: https://doi.org/10.3748/wjg. v21.i12.3579.

15. Tseng HS, Chen CY, Chan WP, Chiang JH. Percutaneous transgastric computed tomography-guided biopsy of the pancreas using large needles. World J Gastroenterol. 2009;15(47):5972-5. doi: https://doi.org/10.3748/wjg.15.5972.

16. Berger H, Permanetter W, Steiner W, Markl A. [Fine-needle and incisional biopsy technics in the percutaneous puncture of abdominal space-occupying lesions]. Radiologe. 1988;28(6):265-8.

17. Gupta S, Nguyen HL, Morello FA, Jr., Ahrar K, Wallace MJ, Madoff DC, et al. Various approaches for CT-guided percutaneous biopsy of deep pelvic lesions: anatomic and technical considerations. Radiographics. 2004;24(1):175-89. doi: https://doi.org/10. 1148/rg.241035063.

18. Balen FG, Little A, Smith AC, Theis BA, Abrams KR, Houghton $\mathrm{J}$, et al. Biopsy of inoperable pancreatic tumors does not adversely influence patient survival time. Radiology. 1994;193(3):753-5. doi: https://doi.org/10.1148/radiology.193.3.7526415.

19. Redfield RR, Kaufman DB, Odorico JS. Diagnosis and Treatment of Pancreas Rejection. Curr Transplant Rep. 2015;2(2):169-75. doi: https://doi.org/10.1007/s40472-015-0061-x.

20. Kuo PC, Johnson LB, Schweitzer EJ, Klassen DK, Hoehn-Saric EW, Weir MR, et al. Solitary pancreas allografts. The role of percutaneous biopsy and standardized histologic grading of rejection. Arch Surg. 1997;132(1):52-7. doi: https://doi.org/10.1001/archs urg.1997.01430250054012.

21. Malek SK, Potdar S, Martin JA, Tublin M, Shapiro R, Fung JJ. Percutaneous ultrasound-guided pancreas allograft biopsy: a single-center experience. Transplant Proc. 2005;37(10):4436-7. doi: https://doi.org/10.1016/j.transproceed.2005.10.023.

22. Klassen DK, Weir MR, Cangro CB, Bartlett ST, Papadimitriou JC, Drachenberg CB. Pancreas allograft biopsy: safety of percutaneous biopsy-results of a large experience. Transplantation. 2002;73(4):553-5. doi: https://doi.org/10.1097/00007890-20020 2270-00011.

23. Atwell TD, Gorman B, Larson TS, Charboneau JW, Ingalls Hanson BM, Stegall MD. Pancreas transplants: experience with 232 percutaneous US-guided biopsy procedures in 88 patients. Radiology. 2004;231(3):845-9. doi: https://doi.org/10.1148/radiol.23130 30277.

24. Banks PA, Freeman ML. Practice guidelines in acute pancreatitis. Am J Gastroenterol. 2006;101(10):2379-400. doi: https://doi.org/ 10.1111/j.1572-0241.2006.00856.x.

25. Baron TH, DiMaio CJ, Wang AY, Morgan KA. American Gastroenterological Association Clinical Practice Update: Management of Pancreatic Necrosis. Gastroenterology. 2020;158(1):67-75.e1. doi: https://doi.org/10.1053/j.gastro.2019.07.064.

26. Tenner S, Baillie J, DeWitt J, Vege SS. American College of Gastroenterology guideline: management of acute pancreatitis. Am J Gastroenterol. 2013;108(9):1400-15; 16. https://doi.org/10.1038/ ajg.2013.218.

27. IAP/APA evidence-based guidelines for the management of acute pancreatitis. Pancreatology. 2013;13(4 Suppl 2):e1-15. https://doi. org/10.1016/j.pan.2013.07.063.

28. Freeman ML, Werner J, van Santvoort HC, Baron TH, Besselink MG, Windsor JA, et al. Interventions for necrotizing pancreatitis: summary of a multidisciplinary consensus conference. Pancreas. 2012;41(8):1176-94. doi: https://doi.org/10.1097/MPA.0b013 e318269c660.

29. Banks PA, Bollen TL, Dervenis C, Gooszen HG, Johnson CD, Sarr MG, et al. Classification of acute pancreatitis--2012: revision of the Atlanta classification and definitions by international consensus. Gut. 2013;62(1):102-11. doi: https://doi.org/10.1136/ gutjnl-2012-302779.

30. Foster BR, Jensen KK, Bakis G, Shaaban AM, Coakley FV. Revised Atlanta Classification for Acute Pancreatitis: A Pictorial Essay. Radiographics. 2016;36(3):675-87. doi: https://doi.org/10. 1148/rg.2016150097.

31. Colvin SD, Smith EN, Morgan DE, Porter KK. Acute pancreatitis: an update on the revised Atlanta classification. Abdom Radiol (NY). 2020;45(5):1222-31. doi: https://doi.org/10.1007/ s00261-019-02214-w.

32. Lenhart DK, Balthazar EJ. MDCT of acute mild (nonnecrotizing) pancreatitis: abdominal complications and fate of fluid collections. AJR Am J Roentgenol. 2008;190(3):643-9. doi: https:// doi.org/10.2214/ajr.07.2761. 
33. Morgan DE, Baron TH, Smith JK, Robbin ML, Kenney PJ. Pancreatic fluid collections prior to intervention: evaluation with MR imaging compared with CT and US. Radiology. 1997;203(3):773-8. doi: https://doi.org/10.1148/radiology. 203.3.9169703.

34. Rodriguez JR, Razo AO, Targarona J, Thayer SP, Rattner DW, Warshaw AL, et al. Debridement and closed packing for sterile or infected necrotizing pancreatitis: insights into indications and outcomes in 167 patients. Ann Surg. 2008;247(2):294-9. doi: https:// doi.org/10.1097/SLA.0b013e31815b6976.

35. Tsiotos GG, Luque-De León E, Sarr MG. Long-term outcome of necrotizing pancreatitis treated by necrosectomy. British Journal of Surgery. 2003;85(12):1650-3. doi: https://doi.org/10.1046/j. 1365-2168.1998.00950.x

36. van Santvoort HC, Besselink MG, Bakker OJ, Hofker HS, Boermeester MA, Dejong CH, et al. A step-up approach or open necrosectomy for necrotizing pancreatitis. N Engl J Med. 2010;362(16):1491-502. doi: https://doi.org/10.1056/NEJMo a0908821.

37. Trikudanathan G, Wolbrink DRJ, van Santvoort HC, Mallery S, Freeman M, Besselink MG. Current Concepts in Severe Acute and Necrotizing Pancreatitis: An Evidence-Based Approach. Gastroenterology. 2019;156(7):1994-2007.e3. doi: https://doi.org/10. 1053/j.gastro.2019.01.269.

38. van Santvoort HC, Bakker OJ, Bollen TL, Besselink MG, Ahmed Ali U, Schrijver AM, et al. A conservative and minimally invasive approach to necrotizing pancreatitis improves outcome. Gastroenterology. 2011;141(4):1254-63. doi: https://doi.org/10.1053/j. gastro.2011.06.073.

39. Nemoto Y, Attam R, Arain MA, Trikudanathan G, Mallery S, Beilman GJ, et al. Interventions for walled off necrosis using an algorithm based endoscopic step-up approach: Outcomes in a large cohort of patients. Pancreatology. 2017;17(5):663-8. doi: https://doi.org/10.1016/j.pan.2017.07.195.

40. van Brunschot S, van Grinsven J, van Santvoort HC, Bakker OJ, Besselink MG, Boermeester MA, et al. Endoscopic or surgical step-up approach for infected necrotising pancreatitis: a multicentre randomised trial. Lancet. 2018;391(10115):51-8. doi: https:// doi.org/10.1016/s0140-6736(17)32404-2.

41. Mortelé KJ, Girshman J, Szejnfeld D, Ashley SW, Erturk SM, Banks PA, et al. CT-guided percutaneous catheter drainage of acute necrotizing pancreatitis: clinical experience and observations in patients with sterile and infected necrosis. AJR Am J Roentgenol. 2009;192(1):110-6. doi: https://doi.org/10.2214/ajr. 08.1116 .

42. Arvanitakis M, Dumonceau JM, Albert J, Badaoui A, Bali MA, Barthet M, et al. Endoscopic management of acute necrotizing pancreatitis: European Society of Gastrointestinal Endoscopy (ESGE) evidence-based multidisciplinary guidelines. Endoscopy. 2018;50(5):524-46. doi: https://doi.org/10.1055/a-0588-5365.

43. Besselink MG, Verwer TJ, Schoenmaeckers EJ, Buskens E, Ridwan BU, Visser MR, et al. Timing of surgical intervention in necrotizing pancreatitis. Arch Surg. 2007;142(12):1194-201. doi: https://doi.org/10.1001/archsurg.142.12.1194.

44. Mier J, León EL, Castillo A, Robledo F, Blanco R. Early versus late necrosectomy in severe necrotizing pancreatitis. Am J Surg. 1997;173(2):71-5. doi: https://doi.org/10.1016/s0002-9610(96) 00425-4.

45. Petrov MS, Chong V, Windsor JA. Infected pancreatic necrosis: not necessarily a late event in acute pancreatitis. World J Gastroenterol. 2011;17(27):3173-6. doi: https://doi.org/10.3748/wjg. v17.i27.3173.

46. Trikudanathan G, Tawfik P, Amateau SK, Munigala S, Arain M, Attam R, et al. Early ( $<4$ Weeks) Versus Standard ( $\geq 4$ Weeks) Endoscopically Centered Step-Up Interventions for Necrotizing
Pancreatitis. Am J Gastroenterol. 2018;113(10):1550-8. doi: https://doi.org/10.1038/s41395-018-0232-3.

47. Banks PA, Gerzof SG, Langevin RE, Silverman SG, Sica GT, Hughes MD. CT-guided aspiration of suspected pancreatic infection: bacteriology and clinical outcome. Int J Pancreatol. 1995;18(3):265-70. doi: https://doi.org/10.1007/bf02784951.

48. Banks PA. Pro: Computerized tomographic fine needle aspiration (CT-FNA) is valuable in the management of infected pancreatic necrosis. Am J Gastroenterol. 2005;100(11):2371-2. doi: https:// doi.org/10.1111/j.1572-0241.2005.00328_1.x.

49. Pappas TN. Con: Computerized tomographic aspiration of infected pancreatic necrosis: the opinion against its routine use. Am J Gastroenterol. 2005;100(11):2373-4. doi: https://doi.org/10. 1111/j.1572-0241.2005.00328_2.x.

50. Rau B, Pralle U, Mayer JM, Beger HG. Role of ultrasonographically guided fine-needle aspiration cytology in the diagnosis of infected pancreatic necrosis. Br J Surg. 1998;85(2):179-84. doi: https://doi.org/10.1046/j.1365-2168.1998.00707.x.

51. Bassi C, Marchegiani G, Dervenis C, Sarr M, Abu Hilal M, Adham M, et al. The 2016 update of the International Study Group (ISGPS) definition and grading of postoperative pancreatic fistula: 11 Years After. Surgery. 2017;161(3):584-91. doi: https:// doi.org/10.1016/j.surg.2016.11.014.

52. Vollmer CM, Jr., Sanchez N, Gondek S, McAuliffe J, Kent TS, Christein JD, et al. A root-cause analysis of mortality following major pancreatectomy. J Gastrointest Surg. 2012;16(1):89-102; discussion -3. https://doi.org/10.1007/s11605-011-1753-x.

53. Gouma DJ, van Geenen RC, van Gulik TM, de Haan RJ, de Wit LT, Busch OR, et al. Rates of complications and death after pancreaticoduodenectomy: risk factors and the impact of hospital volume. Ann Surg. 2000;232(6):786-95. doi: https://doi.org/10. 1097/00000658-200012000-00007.

54. Vin Y, Sima CS, Getrajdman GI, Brown KT, Covey A, Brennan MF, et al. Management and outcomes of postpancreatectomy fistula, leak, and abscess: results of 908 patients resected at a single institution between 2000 and 2005. J Am Coll Surg. 2008;207(4):490-8. doi: https://doi.org/10.1016/j.jamcollsurg. 2008.05.003.

55. Knaebel HP, Diener MK, Wente MN, Büchler MW, Seiler CM. Systematic review and meta-analysis of technique for closure of the pancreatic remnant after distal pancreatectomy. Br J Surg. 2005;92(5):539-46. doi: https://doi.org/10.1002/bjs.5000.

56. Callery MP, Pratt WB, Kent TS, Chaikof EL, Vollmer CM, Jr. A prospectively validated clinical risk score accurately predicts pancreatic fistula after pancreatoduodenectomy. J Am Coll Surg. 2013;216(1):1-14. doi: https://doi.org/10.1016/j.jamcollsurg.2012. 09.002 .

57. McMillan MT, Malleo G, Bassi C, Allegrini V, Casetti L, Drebin JA, et al. Multicenter, Prospective Trial of Selective Drain Management for Pancreatoduodenectomy Using Risk Stratification. Ann Surg. 2017;265(6):1209-18. doi: https://doi.org/10.1097/sla. 0000000000001832.

58. Martin AN, Narayanan S, Turrentine FE, Bauer TW, Adams RB, Zaydfudim VM. Pancreatic duct size and gland texture are associated with pancreatic fistula after pancreaticoduodenectomy but not after distal pancreatectomy. PLoS One. 2018;13(9):e0203841. doi: https://doi.org/10.1371/journal.pone.0203841.

59. Ecker BL, McMillan MT, Allegrini V, Bassi C, Beane JD, Beckman RM, et al. Risk Factors and Mitigation Strategies for Pancreatic Fistula After Distal Pancreatectomy: Analysis of 2026 Resections From the International, Multi-institutional Distal Pancreatectomy Study Group. Ann Surg. 2019;269(1):143-9. doi: https://doi.org/10.1097/sla.0000000000002491.

60. Zink SI, Soloff EV, White RR, Clary BM, Tyler DS, Pappas TN, et al. Pancreaticoduodenectomy: frequency and outcome of post-operative imaging-guided percutaneous drainage. Abdom 
Imaging. 2009;34(6):767-71. doi: https://doi.org/10.1007/ s00261-008-9455-x.

61. Cronin CG, Gervais DA, Castillo CF, Mueller PR, Arellano RS. Interventional radiology in the management of abdominal collections after distal pancreatectomy: a retrospective review. AJR Am J Roentgenol. 2011;197(1):241-6. doi: https://doi.org/10.2214/ajr. 10.5447.

62. Witzigmann H, Diener MK, Kienkötter S, Rossion I, Bruckner T, Bärbel W, et al. No Need for Routine Drainage After Pancreatic Head Resection: The Dual-Center, Randomized, Controlled PANDRA Trial (ISRCTN04937707). Ann Surg. 2016;264(3):528-37. doi: https://doi.org/10.1097/sla.0000000000001859.

63. Van Buren G, 2nd, Bloomston M, Hughes SJ, Winter J, Behrman SW, Zyromski NJ, et al. A randomized prospective multicenter trial of pancreaticoduodenectomy with and without routine intraperitoneal drainage. Ann Surg. 2014;259(4):605-12. https://doi. org/10.1097/sla.0000000000000460

64. Van Buren G, 2nd, Bloomston M, Schmidt CR, Behrman SW, Zyromski NJ, Ball CG, et al. A Prospective Randomized Multicenter Trial of Distal Pancreatectomy With and Without Routine Intraperitoneal Drainage. Ann Surg. 2017;266(3):421-31. https:// doi.org/10.1097/sla.0000000000002375

65. Conlon KC, Labow D, Leung D, Smith A, Jarnagin W, Coit DG, et al. Prospective randomized clinical trial of the value of intraperitoneal drainage after pancreatic resection. Ann Surg. 2001;234(4):487-93; discussion 93-4. https://doi.org/10.1097/ 00000658-200110000-00008.

66. Tilara A, Gerdes H, Allen P, Jarnagin W, Kingham P, Fong Y, et al. Endoscopic ultrasound-guided transmural drainage of postoperative pancreatic collections. J Am Coll Surg. 2014;218(1):3340. doi: https://doi.org/10.1016/j.jamcollsurg.2013.09.001.

67. Al Efishat M, Attiyeh MA, Eaton AA, Gönen M, Covey AM, D'Angelica MI, et al. Endoscopic versus percutaneous drainage of post-operative peripancreatic fluid collections following pancreatic resection. HPB (Oxford). 2019;21(4):434-43. doi: https:// doi.org/10.1016/j.hpb.2018.08.010.

68. Pua U, Quek LH. Modified retroperitoneal access for percutaneous intervention after pancreaticoduodenectomy. Korean J Radiol. 2013;14(3):446-50. doi: https://doi.org/10.3348/kjr.2013.14.3. 446.

69. Maher MM, Gervais DA, Kalra MK, Lucey B, Sahani DV, Arellano R, et al. The inaccessible or undrainable abscess: how to drain it. Radiographics. 2004;24(3):717-35. doi: https://doi.org/ 10.1148/rg.243035100.

70. Gervais DA, Brown SD, Connolly SA, Brec SL, Harisinghani MG, Mueller PR. Percutaneous imaging-guided abdominal and pelvic abscess drainage in children. Radiographics. 2004;24(3):737-54. doi: https://doi.org/10.1148/rg.243035107.

71. Baudin G, Chassang M, Gelsi E, Novellas S, Bernardin G, Hébuterne X, et al. CT-guided percutaneous catheter drainage of acute infectious necrotizing pancreatitis: assessment of effectiveness and safety. AJR Am J Roentgenol. 2012;199(1):192-9. doi: https:// doi.org/10.2214/ajr.11.6984.

72. Freeny PC, Hauptmann E, Althaus SJ, Traverso LW, Sinanan M. Percutaneous CT-guided catheter drainage of infected acute necrotizing pancreatitis: techniques and results. AJR Am J Roentgenol. 1998;170(4):969-75. doi: https://doi.org/10.2214/ajr.170.4. 9530046.

73. Young AS, Shyn PB, Johnson OW, Sainani NI, Nawfel RD, Silverman SG. Bending percutaneous drainage catheters to facilitate CT-guided insertion using curved trocar technique. Abdom Radiol (NY). 2017;42(8):2160-7. doi: https://doi.org/10.1007/ s00261-017-1108-5.

74. Rahnemai-Azar AA, Sutter C, Hayat U, Glessing BR, Ammori J, Tavri S. Multidisciplinary Management of Complicated Pancreatitis: An Update for Interventional Radiologists. AJR Am J Roentgenol. 2021. doi: https://doi.org/10.2214/ajr.20.25168.

75. Beland MD, Gervais DA, Levis DA, Hahn PF, Arellano RS, Mueller PR. Complex abdominal and pelvic abscesses: efficacy of adjunctive tissue-type plasminogen activator for drainage. Radiology. 2008;247(2):567-73. doi: https://doi.org/10.1148/radiol. 2472070761.

76. Ross AS, Irani S, Gan SI, Rocha F, Siegal J, Fotoohi M, et al. Dual-modality drainage of infected and symptomatic walled-off pancreatic necrosis: long-term clinical outcomes. Gastrointest Endosc. 2014;79(6):929-35. doi: https://doi.org/10.1016/j.gie. 2013.10.014.

Publisher's Note Springer Nature remains neutral with regard to jurisdictional claims in published maps and institutional affiliations. 